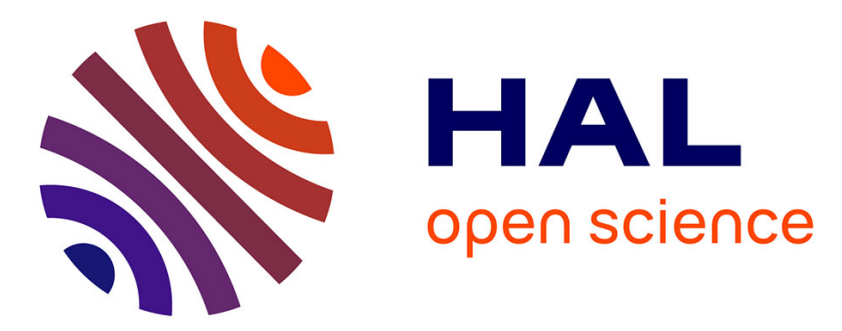

\title{
An updated skeleton void ratio for gravelly sand mixtures considering the effect of grain size distribution
}

Tao Wang, Sihong Liu, Antoine Wautier, François Nicot

\section{To cite this version:}

Tao Wang, Sihong Liu, Antoine Wautier, François Nicot. An updated skeleton void ratio for gravelly sand mixtures considering the effect of grain size distribution. Canadian Geotechnical Journal, 2022, 59 (1), pp.12-23. 10.1139/cgj-2020-0570 . hal-03462438

\section{HAL Id: hal-03462438 \\ https://hal.inrae.fr/hal-03462438}

Submitted on 1 Dec 2021

HAL is a multi-disciplinary open access archive for the deposit and dissemination of scientific research documents, whether they are published or not. The documents may come from teaching and research institutions in France or abroad, or from public or private research centers.
L'archive ouverte pluridisciplinaire HAL, est destinée au dépôt et à la diffusion de documents scientifiques de niveau recherche, publiés ou non, émanant des établissements d'enseignement et de recherche français ou étrangers, des laboratoires publics ou privés.

\section{(c)(1)}

Distributed under a Creative Commons Attribution| 4.0 International License 
An updated skeleton void ratio for gravelly sand mixtures considering the effect

\title{
of grain size distribution
}

\author{
Tao WANG ${ }^{\mathrm{a}, \mathrm{c}, *}$, Sihong LIU ${ }^{\mathrm{a}}$, Antoine WAUTIER ${ }^{\mathrm{b}, \mathrm{c}}$, François NICOT $^{\mathrm{c}}$ \\ ${ }^{a}$ Hohai University, College of Water Conservancy and Hydropower, No.1 Xikang Road, Nanjing 210098, \\ China.
}

bINRAE, Aix-Marseille University, UMR RECOVER, 3275 Rte Cézanne, CS 40061, 13182 Aix-en-

Provence, Cedex 5, France.

'Université Grenoble Alpes, INRAE, UR ETGR, 2 rue de la Papeterie-BP 76, F-38402 St-Martin-d'Hères,

France.

Email address:

tao.wang@inrae.fr; wt@hhu.edu.cn (Tao WANG)

sihongliu@hhu.edu.cn (Sihong LIU)

antoine.wautier@inrae.fr (Antoine WAUTIER)

francois.nicot@inrae.fr (François NICOT) 
Abstract: Recent researches on the behavior of gravelly sands advocate for the use of skeleton void ratio to characterize their density state. Skeleton void ratio corresponds to the void ratio of grains constituting the stress-bearing skeleton. However, such a void ratio relies on parameters difficult to determine in practice, such as the fraction of fine grains that take part actively in the load bearing skeleton. Also, it fails to consider the effect of Grain Size Distribution (GSD) of gravel and sand grains. Therefore, the skeleton void ratio index introduced by Chang et al (2015) is revisited to account for the effect of GSD of both gravel and sand grains. Two semi-empirical equations are developed in this paper to connect GSD parameters with skeleton void ratio parameters. The validity of the proposed equations has been checked for a particular class of gravelly sand materials. A series of specially designed drained triaxial tests on gravelly sands were then conducted. Test results show that it is essential to consider the effect of GSD when using skeleton void ratio index. It also verifies the effectiveness and applicability of the proposed updated skeleton void ratio, which shows advantages in characterizing critical state lines of gravelly sands.

Keywords: Gravelly sand; Skeleton void ratio; Grain size distribution; Sand content; Vibrating compaction test; Drained triaxial test 


\section{Introduction}

Gravelly sands, composed of gravel and sand grains, are commonly encountered in geotechnical engineering. The mass proportion of sand grain in a gravelly sand, together with the size ratio between gravel and sand grain, primarily govern the constitution of its stress-bearing skeleton, which in turn dictates the stress-strain behavior and the resistance it can offer under different loading conditions. At a low sand content $s c$ (and with a sufficiently large size ratio), the mechanical behavior of gravelly sand is governed by intergranular friction between gravel grains. While at a high $s c$ beyond a threshold value $(s c)_{t h}$, the mechanical behavior of gravelly sand is primarily governed by friction characteristics of sand grains (Vallejo, 2001; Vasileva et al., 1971; Saberi et al, 2016; Ng et al, 2017; Gong et al, 2019; Ghorbani et al, 2020; Polito and Sibley, 2020; Yang et al, 2020a; Yang et al, 2020b).

Traditionally, and probably originating from the early work of Terzaghi on the $e-\log p$ ' relation (Terzaghi, 1943) and the following work of Roscoe on critical state soil mechanics (Roscoe and Burland, 1968; Roscoe et al., 1958; Roscoe et al., 1963), the global void ratio $e$ (defined as the total volume of voids divided by the total volume of solids) is selected as one of the most important state variables of soils. However, the global void ratio turned out to be an imperfect index to characterize mechanical behavior of mixed soils (Mitchell, 1993). This is because of the potential non-active participation of the finer grains in the force transmission structure within a mixed soil.

To account for this fact, researchers have introduced the concept of skeleton void ratio $e_{s k}$ (Mitchell, 1993; Vaid, 1994; Kuerbis et al.,1988; Georgiannou et al., 1990; Thevanayagam and Mohan, 2000). Skeleton void ratio corresponds to the void ratio of grains constituting the stressbearing skeleton. The basic idea behind this concept is that in a gravel-sand mixture, not all sand 
grains participate in the load bearing skeleton, and some grains are confined within voids with no contribution to stress transmission. The skeleton void ratio (also named as equivalent intergranular void ratio from Thevanayagam) for a gravel-dominated structure is expressed as (Thevanayagam, 2007; Thevanayagam and Mohan, 2000):

$$
e_{s k}=\frac{e+(1-B) s c}{1-(1-B) s c}
$$

where $e$ is global void ratio, $s c$ denotes the percentage of sand volume content, $B$ represents the portion of sand grains that take part actively in load bearing.

Thanks to the above-mentioned indices of skeleton void ratios, researchers have provided more consistent characterization of such mixed soils in terms of liquefaction susceptibility, shear strength, stiffness and compressive strength (Hazirbaba and Rathje, 2009; Thevanayagam et al., 2002; Ni et al., 2004; Bobei et al., 2009; Carraro et al., 2009; Sitharam et al., 2013; Rahman et al., 2014; Goudarzy et al, 2016; Barnett et al., 2020). Notwithstanding their merits, application of these indices to describe the anticipated mechanical behavior of gravelly sand has faced two issues:

1) Such skeleton void ratio relies on parameters that are difficult to determine in practice, such as the " $B$ parameter" in Equation (1). The determination of such quantity relies on grain scale measurement which is manageable in grain scale numerical simulations (based on a discrete element method) but out of reach in real experiments. Most studies employed the best-fit approach to obtain the $B$ value such that the critical state data of pure gravel grains and its mixture with sand grains share a single Critical State Line (CSL) when plotted in terms of $e_{s k}-\log p^{\prime}$ (Rahman et al, 2008). It indicates that $B$ is a back-calculated value rather than a predicted value based on the nature of the material, and thus the existence of a single CSL of pure gravel grains and its mixtures remains unclear (Yang et al, 2015). 
2) Current skeleton void ratio is proposed and derived from binary mixtures. It assumes that the mixed soil is a two-size particulate system where all gravel grains have a single diameter $D$ and all sand grains have a single diameter $d$ without considering the effect of Grain Size Distribution (GSD) of gravel and sand grains. It works well for relatively uniformly-graded mixed soils, like sandy silt. However, its application to highly polydisperse assemblies, such as gravelly sand, is questionable.

The objective of this study is to put forward to an updated skeleton void ratio which does not contain parameters difficult to determine from an experimental perspective and can incorporate the effect of GSD for cohesionless gravelly sands. It is organized as follows. Firstly, a literature review on the standard skeleton void ratio derived from silt-sand mixture is given. Then, vibrating compaction tests on gravelly sand with different GSD were conducted to evaluate the effect of GSD parameters on the packing of gravelly sand. An updated skeleton void ratio is proposed and built up from the definition given by Chang et al (2015). All the parameters needed to determine this skeleton void ratio have here a clear physical meaning and we show how they can be obtained from simple laboratory tests. Next, a series of specifically-designed drained triaxial tests are presented to assess the relevance of our updated skeleton void ratio in analyzing the stress-strain responses of gravelly sands with varying $s c$. Finally, the advantage of the proposed skeleton void ratio in characterizing CSLs of gravelly sands is shown.

\section{Literature review of the skeleton void ratio concept}

Thevanayagam and co-workers (Thevanayagam, 1998; Thevanayagam, 2007; Thevanayagam and Mohan, 2000; Thevanayagam et al., 2002) qualitatively took into account the contributions of 
the gravel grains and sand grains to the contact force network, which can be classified into the following four cases based on the skeleton structure of the gravelly sand, as shown in Fig. 1:

Case 1: The sand grains are fully confined within the voids formed by gravel grains. This requires that the diameter of sand grain is much smaller than the voids among gravel grains and the sand content is sufficiently small. In the definition of $e_{s k}$, the space occupied by sand grains is then simply considered as void since sand grains do not participate in force transmission:

$$
\left(e_{s k}\right)_{\text {Thevanayagam }}=\frac{e+s c}{1-s c}
$$

This definition is simply the restriction of Mitchell definition (Mitchell, 1993) to the lowest sand content values.

Case 2: When sc increases, the skeleton structure is made up of gravel grains and part of the sand grains which take active participation in the internal contact force network. The rest of sand grains are confined within the voids among gravel grains. The expression of $e_{s k}$ is shown in Equation (1). Equation (1) reduces to Equation (2) when $B=0$. When $B=1, e_{s k}$ equals to $e$, meaning that the all sand act as skeleton grains like gravel grains. In practice, identifying parameter $B$ is not straightforward as $B$ depends on $s c$ and on the relative density of the material (Thevanayagam and Mohan, 2000; Ni et al., 2004).

Case 3: When sc exceeds a sand content threshold $(s c)_{t h}$ but remains below a limit sand content $(s c)_{L}$, sand grains make active contacts among themselves while gravel grains become gradually dispersed and act as embedded reinforcement elements within the matrix of sand grains. The gravelly sand is a kind of sand-dominated structure, and the skeleton void ratio considering the reinforcing effect of gravel grains is:

$$
\left(e_{s k}\right)_{\text {Thevanayagam }}=\frac{e}{s c+\frac{1-s c}{R_{d} m}}
$$


where $R_{d}$ is grain size disparity ratio, e.g. ratio of grain size between gravel and sand grain, and $m$ is a reinforcement factor.

Case 4: When $s c$ increases beyond the limiting sand content $(s c)_{L}$, the reinforcing effect of gravel grains becomes negligible and the behavior of the mixed soil is entirely governed by the sand grain-to-sand grain contact. Since gravel grains are not voids and their volumes do not affect the nature of the force chain in the sand grains, the solid volume of the gravel grains may be ignored, with $e_{s k}$ expressed as:

$$
\left(e_{s k}\right)_{\text {Thevanayagam }}=\frac{e}{s c}
$$

Equation (4) is a special case of Equation (3) when $s c$ is very close to 1, and the term $\frac{1-s c}{R_{d}{ }^{m}}$ is neglected.

As stated above, the skeleton void ratios proposed by Thevanayagam rely on parameters $(B, m$,

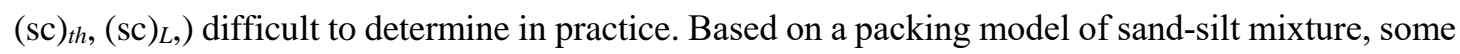
researchers (Chang and Yin, 2011; Yin et al, 2014; Chang et al, 2015; Yin et al, 2016) derived the skeleton void ratio of gravel-dominated gravelly sand:

$$
\left(e_{s k}\right)_{\text {Chang and Yin }}=\frac{e-(a-1) s c}{1-s c}
$$

where $a$ is a material constant reflecting the degree of how sand grains interrupt the gravel grain skeleton.

Similarly, the skeleton void ratio of a sand-dominated structure is:

$$
\left(e_{s k}\right)_{\text {Chang and Yin }}=\frac{e-b}{s c}+b
$$

where $b$ is a material constant reflecting the degree of how gravel grains interrupt the sand grain skeleton.

According to Chang et al (2015), the minimum void ratio of gravelly sand is a function of 
minimum void ratios of pure sand grains $e_{s}$, minimum void ratios of pure gravel grains $e_{g}, s c, a$ and $\mathrm{b}$. An intermediate situation between the gravel-dominated and sand-dominated structure can be characterized by threshold sand content $(s c)_{t h}$. $(s c)_{t h}$ can be deduced by combining the expressions of minimum void ratio of gravel-dominated and sand-dominated structures (the expressions are not shown here, some details can be found in the quoted reference):

$$
(s c)_{t h}=\frac{e_{g}-b}{1+e_{g}+e_{s}-a-b}
$$

where $e_{s}$ and $e_{g}$ are the minimum void ratios of pure sand grains and pure gravel grains, respectively.

The material constants $a$ and $b$ reflect the degree of interaction between gravel and sand grains during packing process, which is related to the GSD of gravel and sand grains. Interaction between gravel and sand grains will inevitably occur during the process of packing, causing the socalled "loosening effect" and "wall effect" shown in Fig. 2 (De Larrard, 1999). Loosening effect in a gravel-dominated structure, corresponds to the situation where added sand grains will push apart gravel grains, leading to a local increase in void volume. Wall effect means (in a sand-dominated structure) that porosity locally increases in the vicinity of close gravel grains as the void space is too narrow to be fully filled by sand grains (see Fig. 2). When $a=0$, Equation (5) reduces to Equation (2), and when $b=0$, Equation (6) reduces to Equation (4), indicating that the skeleton void ratio proposed by Thevanayagam is a special case which neglects the mutual interaction between gravel and sand grains during the process of packing.

\section{An updated skeleton void ratio incorporating the effect of GSD}

In this section, the effect of GSDs of gravel and sand grains is taken into account by conducting 
a series of vibrating compaction tests to build relationships between GSD and skeleton void ratio parameters, namely parameters $a$ and $b$ in Equations (5) and (6). These parameters reflect the degree of interaction between gravel and sand grains during packing process and they are used to capture most of the GSD information of the material.

According to Chang et al (2015), $0 \leq a \leq 1+e_{\mathrm{s}}$ and $0 \leq b \leq e_{\mathrm{g}}$, where $e_{\mathrm{s}}$ and $e_{\mathrm{g}}$ are the minimum void ratios of pure sand grains and pure gravel grains, respectively. For convenience, $a$ and $b$ are thus normalized so that they range between 0 and 1 :

$$
\begin{gathered}
\alpha=\frac{a}{1+e_{s}} \\
\beta=\frac{b}{e_{g}}
\end{gathered}
$$

In order to quantitively account for the effect of GSD on the packing process of gravelly sands, typical GSD parameters are selected, e.g. coefficient of non-uniformity of gravel grains $C_{u g}=$ $\frac{\left(d_{60}\right)_{\text {gravel }}}{\left(d_{10}\right)_{\text {gravel }}}$, coefficient of non-uniformity of sand grains $C_{u s}=\frac{\left(d_{60}\right)_{\text {sand }}}{\left(d_{10}\right)_{\text {sand }}}$ and grain size disparity ratio $R_{d}=\frac{\left(d_{50}\right)_{\text {gravel }}}{\left(d_{50}\right)_{\text {sand }}}$. These three GSD parameters have been shown to have a great effect on the packing density of granular materials (De Larrard, 1999; Li et al, 2015).

\section{Vibrating compaction test}

According to the Unified Soil Classification System (USCS classification, 2017), aggregates with grain size ranging from $4.75 \mathrm{~mm}$ to $20 \mathrm{~mm}$ were selected as gravel grains and grains with grain size below $4.75 \mathrm{~mm}$ and over $0.075 \mathrm{~mm}$ were selected as sand grains. Detailed test program is given in Table 1. A total of seven groups of tests are designed, e.g. $\mathrm{T}_{1}-\mathrm{T}_{7}$, each of which involves a specimen with specific $C_{u g}, C_{u s}$ and $R_{d}$. The individual influence of $C_{u g}$ can be studied by comparing test results of $T_{1}, T_{2}$ and $T_{3}$, and the individual influence of $C_{u s}$ can be studied by comparing test results of $\mathrm{T}_{2}, \mathrm{~T}_{4}$ and $\mathrm{T}$, while the individual influence of $R_{d}$ can be studied by comparing test results 
of $T_{2}, T_{6}$ and $T_{7}$. For every test shown in Table 1, specimens with seven different sand content of $s c=0,0.1,0.3,0.5,0.6,0.7$ and 1 were prepared and tested. Therefore, a total of $7 \times 7=$ 49 specimens were tested.

Each specimen has the same mass of $20 \mathrm{~kg}$ and is prepared with targeted GSD parameters shown in Table 1. The samples were prepared in dry conditions. Given the wide range of grain size, it is not possible to use a sample preparation technique such as dry pluviation. Samples were prepared by rapidly and carefully pouring layers (approximately $2 \mathrm{~cm}$ in thick) into a steel-made cylinder to make sure that segregation of grains did not occur. The cylinder has a size of $20 \mathrm{~cm} \times 23$ $\mathrm{cm}$ (inner diameter $\times$ height) and it is fixed on a shaking table. An additional load was then placed on the top of the specimen to exert a pressure of $14 \mathrm{kPa}$. Then, the shaking table began to vibrate with a vibrating frequency of $60 \mathrm{~Hz}$ and an amplitude of $2 \mathrm{~mm}$. The vibrating lasted to achieve the minimum void ratio. After the vibrating, the load was taken out of the cylinder and the height of the specimen was measured to calculate its void ratio. After vibrating compaction, no obvious segregation of gravel and sand grains can be found.

\section{Test results and discussions: how GSD parameters affect $\alpha$ and $\beta$}

Figure 3 shows the V-shape relationship between minimum void ratio and $s c$ under different GSD parameters of $C_{u g}, C_{u s}$ and $R_{d}$. When $s c$ is low, minimum void ratio decreases with $s c$. As $s c$ continues to increase, the reversed trend is observed (i.e., the minimum void ratio increases). The turning point corresponds to the $(s c)_{t h}$. It can be seen that $(s c)_{t h}$ ranges between $0.50-0.65$, which is larger than the threshold silt content of sand-silt mixture (about 0.25-0.35). Large threshold sand content for gravelly sand is also reported by other researchers, for instance $0.50-0.60$ from Chen et al (2018), and around 0.50 from Amini and Chakravrty (2004). The reason for the large threshold 
sand content may be the use of angular gravel in our tests, which cause large voids among gravel grains. According to Chang et al (2015), parameters $a$ and $b$ can be obtained from the slopes of the bilinear lines, the slope of the left line (gravel-dominated structure) is $1+e_{g}-a$, and the slope of right line (sand-dominated structure) is $e_{s}-b . \alpha$ and $\beta$ are calculated with the help of Equations (8)-(9) and shown in Fig. 4. It should be recalled here that $\alpha$ and $\beta$ reflect the degree of interaction between gravel and sand grains.

According to Figs. 3-4, the individual influence of each of these three GSD parameters $\left(C_{u g}\right.$, $C_{u s}$ and $\left.R_{d}\right)$ on $(s c)_{t h}, \alpha$ and $\beta$ is analyzed as follows:

(a) (sc) th decreases with $C_{u g}$, while both $\alpha$ and $\beta$ increase with $C_{u g}$. When $C_{u g}$ increases, the composition of gravel grains becomes less uniform, which means that gravel grains contain more larger and smaller grains than the case of a smaller $C_{u g}$. Thus, the size of voids formed by gravel grains decreases. If now sand grains of the same size are added into gravel-dominated structure, less sand grains are needed to fully fill the voids among gravel grains. Therefore, $(s c)_{t h}$ will decrease $C_{u g}$. Since the size of voids formed by gravel grains decreases, the gravel grain skeleton will be more altered by added sand grains, hence $\alpha$ increases. For a sanddominated structure, if gravel grains with larger $C_{u g}$ are added, the wall effect shown in Fig. 2 becomes more pronounced because the size of voids among gravel grains decreases. Vicinity of gravel grains becomes more difficult to be filled by sand grains, making $\beta$ increase.

(b) (sc) th decreases with $C_{u s}$, while both $\alpha$ and $\beta$ increase with $C_{u s}$. When $C_{u s}$ increases, sand grains contain a greater number of large size sand grains than the case when $C_{u s}$ is small. Therefore, a gravel-dominated structure needs less sand grains to fill its voids, i.e. $(s c)_{t h}$ decreases with $C_{u s}$. Adding these sand grains into a gravel-dominated structure will cause more 
altering of the gravel grain supported fabric, and thus $\alpha$ increases. In the case of adding the same gravel grains to a sand-dominated structure with a larger $C_{u s}$, the wall effect becomes more pronounced because the greater number of large size sand grains makes the interface vicinity of two close gravel grains more difficult to be filled. Therefore, $\beta$ increases.

(c) (sc) $)_{t h}$ increases with $R_{d}$, while both $\alpha$ and $\beta$ decrease with $R_{d}$. When $R_{d}$ increases, the ratio of voids size among gravel grains and $\left(d_{50}\right)_{\text {sand }}$ increases. Therefore, $(s c)_{t h}$ increases. In the case of adding sand grains into a gravel-dominated structure, the altering of gravel grain skeleton caused by added sand grains decreases, and thus $\alpha$ decreases. In the case of adding gravel grains to the assembly of sand grains, due to the much smaller size of sand grains, the interface vicinity of two close gravel grains becomes easier to be filled, leading to less distortion of sand grain structure, and thus $\beta$ decreases.

\section{Prediction of $\alpha$ and $\beta$ and validation}

From above-mentioned test results, GSDs of both gravel and sand grains will greatly influence the degree of mutual interaction between gravel and sand grains during the process of packing. The mutual interaction (i.e. $\alpha$ and $\beta$ ) will become more pronounced with increasing $C_{u g}, C_{u s}$ and decreasing $R_{d}$. Two functions $\alpha=F_{1}\left(C_{u g}, C_{u f}, R_{d}\right), \beta=F_{2}\left(C_{u g}, C_{u f}, R_{d}\right)$ are expected to predict $\alpha$ and $\beta$ incorporating the effect of $C_{u g}, C_{u s}$ and $R_{d}$. These functions should be able to correctly simulate the effect of $C_{u g}, C_{u s}$ and $R_{d}$ stated above and yet have a simple form. In addition, they should ensure $\alpha$ and $\beta$ range between 0 and 1. Equations (10) and (11) satisfy such requirements:

$$
\begin{gathered}
\alpha=\exp \left(-R_{d}^{0.5} / C_{u g} C_{u s}\right) \\
\beta=\exp \left(-R_{d} / C_{u g} C_{u s}^{0.5}\right)
\end{gathered}
$$


Equations (10) and (11) ensures $\alpha$ and $\beta$ range between 0 and 1 and $\alpha$ and $\beta$ increase with the increase in $C_{u g}, C_{u s}$ and decrease in $R_{d}$. To verify the fitting ability of Equations (10) and (11), comparison between experimental data of $\alpha, \beta$ and predicted data using Equations (10) and (11) is shown in Fig. 5. It can be seen that Equations (10) and (11) give good predictions of $\alpha, \beta$. Furthermore, the experimental and predicted minimum void ratios using Equations (10) and (11) (the slope of the bilinear lines can be determined by $\alpha$ and $\beta$ ) are compared in Fig. 6, which also shows good agreement between predicted and experimental values.

To further explore the validity of Equations (10) and (11), an additional series of vibrating compaction tests were conducted. In these additional tests, gravel and sand with different mineralogies from those used in the above tests were used. Besides, the maximum diameter of the gravel grains is $40 \mathrm{~mm}$, much bigger that used in above tests $(20 \mathrm{~mm})$. The GSD parameters are $C_{u g}=2.57, C_{u s}=7.32$, and $R_{d}=9.38$, and the GSD of gravelly sand samples is shown in Fig. 7 . We can calculate $a$ and $b$ from Equations (8)-(11). Then, the minimum void ratio of gravelly sand with different sand contents can be predicted, as the slope of the bilinear relationship between minimum void ratio and sand content is related to $a$ and $b$ (the slope of the left line is $1+e_{g}-$ $a$, and the slope of right line is $e_{s}-b$ ). Experimental and predicted minimum void ratios are compared in Fig. 8. It can be seen that the predicted minimum void ratios agree well with experimental results, which, to some extent, shows the effectiveness of Equations (10) and (11) for gravelly sand with different maximum grain size and grain mineralogy.

Now, if we combine Equations (5), (8), and (10), the $e_{s k}$ for a gravel-dominated structure expresses as:

$$
e_{s k}=\frac{e+s c}{1-s c}-\frac{s c\left(1+e_{s}\right)}{1-s c} \exp \left(-R_{d}^{0.5} / C_{u c} C_{u f}\right)
$$


Combining Equations (6), (9), and (11), the $e_{s k}$ for a sand-dominated structure is given by:

$$
e_{s k}=\frac{e}{s c}-\frac{e_{g}(1-s c)}{s c} \exp \left(-R_{d} / C_{u g} C_{u s}^{0.5}\right)
$$

When the GSD of gravelly sand is given, parameters $a, b$ can be determined by Equations (8)-(11) through only two vibrating compaction tests on pure gravel and pure sand to determine $e_{c}$ and $e_{s} .(s c)_{t h}$ can also be determined from Equation (7). If $s c$ of a gravelly sand sample is less than $(s c)_{t h}$, the mixture corresponds to a gravel-dominated structure and its skeleton void ratio can be determined from Equation (12). Otherwise, it is a sand-dominated structure and its skeleton void ratio can be determined by Equation (13). In next section, we investigate the effectiveness and applicability of the proposed skeleton void ratios in drained triaxial tests.

\section{Drained triaxial compression tests}

\section{Test objectives}

A series of drained triaxial tests on gravelly sands prepared with different $s c, e$, and $e_{s k}$ were conducted. The objectives of this section are: 1) to experimentally evaluate how $s c$ influences the stress-strain response of gravelly sands, 2) to verify the effectiveness of the proposed $e_{s k}$ to interpret experimental results, 3) to assess the uniqueness of the stress-strain response of gravelly sands prepared with the same $e_{s k}$.

In order to challenge the objectives listed above, three different series of tests were designed, as shown in Table 2. In Test Series A, specimens with different $s c$ were prepared at the same $e$ to study the effect of $s c$ on stress-strain responses of gravelly sands. In Test Series B and C, specimens were prepared at the same $e_{s k}$ (calculated from Equations (12) and (13)) to compare their stressstrain responses. In Test Series B, specimens are all at low $s c$ to ensure they are gravel-dominated 
structures, while in Test Series C, specimens all have high $s c$ to ensure they are sand-dominated structures. In addition, the effectiveness of both the updated skeleton void ratios (Equations (12) and (13)) and those proposed by Thevanayagam which do not consider the effect of GSD (Equations (2) and (4)) are evaluated.

\section{Test materials and procedures}

Gravelly sands with different $s c$ were prepared by mixing gravel with different amounts of sand by weight. Note that gravel and sand used in triaxial tests have almost the same specific gravity, and thus sand grain volume fraction equals to weight fraction. The index properties of tested gravel and sand are shown in Table 3. Fig. 9 shows the GSDs of gravelly sands with different $s c(s c=0,0.1$, $0.3,0.5,0.7$ and 1). Given the wide range of grain size, it was not possible to use a sample preparation technique such as dry pluviation. Cylindrical specimens, $101 \mathrm{~mm}$ in diameter and 200 $\mathrm{mm}$ in height, were prepared by rapidly and carefully pouring gravelly sands by five layers into the triaxial mold to make sure that segregation of grains did not occur. Each layer was then compacted by gently tamping until reaching a specified target void ratio. The procedure was similar for each layer until the final target void ratio was reached. The target void ratios of the specimens were selected to satisfy specific constraints on global and skeleton void ratios designed in Table 2. Then, specimens were saturated to obtain sample saturation with Skempton's B value ${ }^{1}$ larger than 0.95 , and confining pressures ranging from $150 \mathrm{kPa}$ to $600 \mathrm{kPa}$ were applied. Note that a Skempton's B value larger than 0.95 is usually recommended in experiments. In the present study, the mean value for all tests is indeed 0.976 and tests with the smallest Skempton's B values were not excluded since

\footnotetext{
Skempton's B value corresponds to the fraction of the increase in pore water pressure $\Delta u$ that impacts the mean total stress $\Delta \sigma_{c}$. Perfect undrained conditions are achieved when $\mathrm{B}=1$ (fully saturated pore space).
} 
they gave consistent results (reported in Appendix). All specimens were sheared under the conventional drained triaxial compression conditions with a constant vertical displacement rate of $0.8 \mathrm{~mm} / \mathrm{min}$. The tests were ceased at an axial strain of $25 \%$ to make sure specimens had reached critical state. The axial load, axial deformation, and volume of the expelled water from specimen were recorded using a built-in data acquisition system. The volume change of specimens was calculated from the volume of the expelled water from specimens.

$e$ and $e_{s k}$ of specimens before and after consolidation under different confining pressures are listed in Table 4. It can be seen from Table 4 that in Test Series A under the same confining pressure, $e$ of specimens with different $s c$ after consolidation are similar, indicating that these specimens can be compared at a given similar $e$ value. In Test Series B and $\mathrm{C}$, the differences of $e_{s k}$ in specimens with different $s c$ after consolidation are minor, indicating that these specimens can be compared at a given similar $e_{s k}$ values.

\section{Test results and discussions}

1) Test series A (compared at a similar $e$ after consolidation)

Reproducibility assessment is first carried out and shown in Appendix. Fig. 10 illustrates variations of $q$ and $\varepsilon_{v}$ with axial strain $\varepsilon_{1}$ for specimens prepared with different $s c$ at similar $e$ under confining pressures of $150 \mathrm{kPa}, 300 \mathrm{kPa}$ and $600 \mathrm{kPa}$. It should be noted that (sc) th is about 0.54 . Therefore, specimens with sc lower than 0.54 are gravel-dominated structure, otherwise it is sand-dominated. In Fig. 10, for better comparison, curves of specimens with the same dominated structure are presented in the same figure. From Fig. 10(a)(c)(e), all are gravel-dominated, it can be seen that peak shear strength of gravelly sands decreases with the increase in $s c$. When the confining pressure is low $\left(\sigma_{3}=150 \mathrm{kPa}\right)$, specimens in Fig. 10(a) reach the same critical state strength. 
While at larger confining pressure $\left(\sigma_{3}=300 \mathrm{kPa}\right.$ and $600 \mathrm{kPa}$ shown in Fig.10(c) and Fig. 10(e), respectively), their critical state strengths exhibits some slight differences but with close values. At the same time, more contractive behavior is observed with the increase in $s c$, although the so-called critical state is not strictly attained because $\varepsilon_{v}$ still evolves slightly at large strain. On the other hand, for sand-dominated specimens shown in Fig. 10(b)(d)(f), peak shear strength increases and more dilative behavior is observed with the increase in $s c$. Interestingly, the critical state strength for sand-dominated specimens with different $s c$, again, converges at large strain.

Test results observed in Fig. 10 are interpreted here from the perspective of $e_{s k} . e_{s k}$ of specimens in Test Series A are calculated from Equations (12) and (13) and listed in Table 5. It can be seen that the increase in $s c$ in specimens prepared at the same $e$ leads to an increase in $e_{s k}$ for gravel-dominated specimens, e.g. specimens with $f c=0,0.1,0.3$, and 0.5 . It is pointed out by Thevanayagam and Mohan (2000) that a gravelly sand (gravel-dominated structure) has similar stress-strain response as pure gravel grain if global void ratio of the pure gravel grain equals to the skeleton void ratio of the gravelly sand. Thus, gravelly sand behaves rather like a "looser" pure gravel specimen $(s c=0)$ with the increase in $s c$, resulting in decreasing peak strength with the same critical state strength according to the critical state theory. It also explains why a more contractive behavior is observed with the increase in $s c$, which is a typical volumetric response from dense to loose specimens. Similarly, for a sand grain supported fabric, e.g. $s c=0.7$ and 1 , specimen with $s c$ of 0.7 has larger $e_{s k}$ than that of pure sand $(s c=1)$, and thus it behaves rather like a loose pure sand specimen. Therefore, larger peak strength, larger dilatancy, and the same critical state strength are observed for the specimen with $s c=1$.

2) Test series $\mathrm{B}$ and $\mathrm{C}$ (compared at a similar $e_{s k}$ after consolidation) 
As shown in Table 2, the objectives of Test series B and C are to compare stress-strain responses of both gravel-dominated and sand-dominated gravelly sands at the same $e_{s k}$. Variations of $q$ and $\varepsilon_{v}$ with axial strain $\varepsilon_{1}$ for specimens with the same $e_{s k}$ (computed by Equations (12) and (13)) are shown in Fig. 11. Similar stress-strain response is observed for gravel-dominated specimens (Fig. 11(a)) and for sand-dominated specimens (Fig. 11(b)).

It should be noted that the $e_{s k}$ listed above (computed from Equations (12) and (13)) are derived for gravelly sand by considering the effect of GSD. For comparison, it is interesting to see how specimens behave with the same $e_{s k}$ computed from Equations (2) and (4) derived for silty sand which inherently do not consider the effect of GSD. Stress-strain responses of specimens with the same $e_{s k}$ computed by Equations (2) and (4) are illustrated in Fig. 12. It can be seen from Fig. 12 that these specimens do not behave similarly as it can be observed in Fig. 11. It can also be pointed out from Fig. 12 that specimens with $s c=0.1$ and $s c=0.25$ behave like denser pure gravel samples, while specimens with $s c=0.7$ and $s c=0.85$ behave like denser pure sand samples. Equations ( 2$)$ and (4) are special cases with $a=0$ and $b=0$ in Equation (5) and (6), where $a$ and $b$ both reflect mutual interaction between gravel and sand grains. It can be inferred that neglecting the mutual interaction between gravel and sand grains will underestimate the needed value of $e$ to reach the same $e_{s k}$. The above analysis emphasizes the significance to consider the effect of GSD to derive $e_{s k}$ for gravelly sands.

Results in Test series B and C shown in Fig. 11 also highlight that stress-strain responses of gravelly sands with varying $s c$ can be predicted by only knowing the stress-strain response of pure gravel or sand with $e$ equal to the $e_{s k}$ of gravelly sand. 


\section{Advantage of the updated skeleton void in characterizing CSLs of gravelly sands}

Mixed soils with different $s c$ have different GSDs and thus essentially have different CSLs, as reported by many researchers (Been and Jefferies, 1985; Zlatovic and Ishihara, 1995; Thevanayagam et al., 2002; Bouckovalas et al, 2003; Yang et al ,2006; among others). These researchers found that the location of the CSLs would move downward from the pure gravel grain specimen until it reaches the threshold fine content, and then they would move upward to the position of pure sand grain specimen. CSLs of gravelly soil with different $s c$ are plotted in Fig. 13. It can be seen that the location of CSLs shows a similar trend as that reported by Yang et al (2006). Above-mentioned test results shown in Fig. 10 can serve well to interpret the dependence of CSLs with $s c$. For a gravel-dominated specimen, more contractancy is observed with the increase in $s c$ which widens the gap between current void ratio and critical void ratio (specimens are prepared at the same initial void ratio) and leads to the downward of the CSL. On the other hand, for a sanddominated specimen, the increase in $s c$ results in more dilatancy and narrows the gap. Therefore, CSL will move upwards. Besides, it can be found the slopes of these CSLs are different. It may result from the difference in grain shape of gravel and sand. It is consistent with the results from other researchers who have found that grain shape has great effect on the critical state lines of sandsilt mixtures (e.g. Yang et al, 2006; Yang and Wei 2012; Wei and Yang 2014)

Thevanayagam (1998) early noted that critical state data of the pure gravel grains and its mixture with sand grains, when plotted in terms of $e_{s k}-p^{\prime}$, fall within a narrow band to give a single CSL. This attractive finding was then verified by some experimental studies. However, in their studies $e_{s k}$ is usually calculated from Equation (1) and the parameter $B$ is normally determined by a 
best-fit approach. This back-calculated method to determine $B$ causes some doubt on the uniqueness of CSL of pure gravel grains and its mixtures (Yang et al, 2015). Yang et al (2015) also found that position of the best-fit CSL is different from the position of the CSL of the pure gravel grain determined by using the critical state data. The CSL of the pure gravel grain is therefore no longer unique as it depends on the sand added, thus violating the principle of the critical state approach that specifies the existence of a unique CSL for a given gravel grain.

To explore the uniqueness of CSLs in the $e_{s k}-p$ ' plane for pure gravels and its mixtures (or pure sands and its mixtures), we calculate the $e_{s k}$ from Equation (12) for a gravel-dominated structure and from Equation (13) for a sand-dominated structure. It should be noted that when using Equation (12) and (13), there are no arbitrarily-determined parameters, such as $B$, but instead all the parameters are determined from the materials' GSD. Pure gravel and pure sand have different CSLs because they have different grain shapes and GSDs. Therefore, for a clear view, we separately plot the critical state data of gravel-dominated structure (Fig. 14a) and sand-dominated structure (Fig. $14 \mathrm{~b})$ in $e_{s k}-p$ ' plane. It can be seen from Fig. $14 \mathrm{a}$, for the gravel-dominated specimens $(s c=0,0.1$, 0.3 and 0.5 ), that a single CSL of pure gravel grains $(s c=0)$ is shared with gravelly sands for different $s c(s c=0,0.1,0.3$ and 0.5$)$. Similarly, as shown in Fig. 14b, for the sand-dominated specimens $(s c=0.7,1)$, the critical state data of gravelly sands with $s c=0.7$ fall in the vicinity of the CSL of the pure sand $(s c=1)$, meaning that they share the same CSL in the $e_{s k}-p$ ' plane. These results suggest that there is a unique CSL for a pure gravel grain and its mixtures which are all gravel-dominated in response to the above doubts. It is also valid for pure sand grain and sand-dominated mixtures. For the sake of comparison, we plot the CSLs in which $e_{s k}$ is calculated from Equations (2) and (4 which do not consider the effect of GSD in Figs. 14(c) and (d). It can be observed that for gravel- 
dominated and sand-dominated structures, pure gravel grain (or pure sand grain) does not share a single CSL with its mixture. It underlines the importance to consider the effect of GSD for highly polydisperse mixed soils, such as gravelly sand.

If we use the simple linear function of the critical state line, the critical state line in $e_{s k}-\log$ p' plane can be written as:

$$
\left(e_{c r}\right)_{s k}=\left(e_{\Gamma}\right)_{s k}-\lambda_{s k} \lg p^{\prime}
$$

Where $\left(e_{c r}\right)_{s k}$ is critical skeleton void ratio; $\left(e_{\Gamma}\right)_{s k}$ and $\lambda_{s k}$ are model parameters and can be determined by directly fitting the critical state data of pure gravel or pure sand.

\section{Concluding remarks}

An index of skeleton void ratio for highly polydisperse mixed soils, i.e. gravelly sands, is proposed by incorporating the effects of typical GSD parameters. Two simple semi-empirical equations are developed to connect GSD parameters $\left(C_{u g}, C_{u s}\right.$ and $\left.R_{d .}\right)$ with skeleton void ratio parameters $\alpha$ and $\beta$. The validity of the proposed equations has been checked for a particular class of gravelly sand materials. Further tests i) on gravelly sands with wider range of GSDs and ii) on sand and/or the gravel materials with different grain shapes are expected to extend the validity of the proposed skeleton void ratio.

Several specially-designed drained triaxial tests were carried out to verify the effectiveness and applicability of the proposed skeleton void ratio from an experimental point of view. The proposed skeleton void ratio proves to be effective and can be used to interpret the results of stress-strain responses of gravelly sands with varying sand contents along triaxial loading path. Test results also highlight the interest to consider the effect of GSD when using skeleton void ratio index. 
By using this updated skeleton void ratio, no arbitrarily-determined parameters are needed, but instead all the parameters are determined from the materials' GSD. This updated skeleton void ratio also proves to have advantages in characterizing the CSLs of gravelly sand, which guarantees a unique CSL in $e_{s k}-p$ ' plane of pure gravel (or pure sand) and its mixtures.

The proposed skeleton void ratio is expected to be applied to some constitutive models for engineering application, for instance on rockfill dams.

\section{Acknowledgements}

This work was supported by "The Joint Funds of the National Natural Science Foundation of China” (Grant No. U1765205), “The Fundamental Research Funds for the Central Universities” (Grant No.2019B71014) and "Postgraduate Research and Practice Innovation Program of Jingsu Province" (Grant No.SJKY19_0480). The first author also would like to appreciate the financial support of the China Scholarship Council (CSC) (Grant No. 201906710002) for his joint research in INRAE (Grenoble Alpes University), France.

\section{References}

Amini, F., and Chakravrty, A. 2004. Liquefaction testing of layered sand-gravel composites. Geotechnical Testing Journal, 27(1): 36-46.

ASTM. Standard Practice for Classification of Soils for Engineering Purposes (Unified Soil Classification System, D2487-17, West Conshohocken, PA, 2017)

Barnett, N., Rahman, M. M., Karim, M. R., Nguyen, H. K., Carraro, J. A. H. 2020. Equivalent state theory for mixtures of sand with non-plastic fines: A DEM investigation. Géotechnique, 1-18. Benahmed, N., Nguyen, T. K., Hicher, P. Y., Nicolas, M. 2015. An experimental investigation into the effects of low plastic sand content on the behaviour of sand/silt mixtures. European Journal 
of environmental and civil engineering, 19(1): 109-128.

Bobei, D. C., Lo, S. R., Wanatowski, D., Gnanendran, C. T., Rahman, M. M. 2009. Modified state parameter for characterizing static liquefaction of sand with fines. Canadian Geotechnical Journal, 46(3): 281-295.

Bouckovalas, G. D., Andrianopoulos, K. I., Papadimitriou, A. G. 2003. A critical state interpretation for the cyclic liquefaction resistance of silty sands. Soil Dynamics and Earthquake Engineering, 23(2): 115-125.

Carraro, J. A. H., Prezzi, M., Salgado, R. 2009. Shear strength and stiffness of sands containing plastic or nonplastic sand. Journal of geotechnical and geoenvironmental engineering, 135(9): $1167-1178$.

Chang, C. S., Deng, Y., Yang, Z. 2017. Modeling of minimum void ratio for granular soil with effect of particle size distribution. Journal of Engineering Mechanics, 143(9):04017060.

Chang, C. S., Wang, J. Y., Ge, L. 2015. Modeling of minimum void ratio for sand-silt mixtures. Engineering geology, 196: 293-304.

Chang, C. S., and Yin, Z. Y. 2011. Micromechanical modeling for behavior of silty sand with influence of sand content. International Journal of Solids and Structures, 48(19): 2655-2667.

Chen, G. X., Wu, Q., Sun, T., Zhao, K., Zhou, E. Q., Xu, L. Y., Zhou, Y. G. 2018. Cyclic behaviors of saturated sand-gravel mixtures under undrained cyclic triaxial loading. Journal of Earthquake Engineering, 1-34, DOI: 10.1080/13632469.2018.1540370.

De Larrard, F. 1999. Concrete mixture proportioning: a scientific approach. CRC Press.

Georgiannou, V. N., Burland, J. B., Hight, D. W. 1990. The undrained behavior of clayey sands in triaxial compression and extension. Geotechnique, 40(3): 431-449. 
Ghorbani, A., Eslami, A., Nezhad Moghadam, M. 2020. Effect of non-plastic silt on liquefaction susceptibility of marine sand by transparent laminar shear box in shaking table. International Journal of Geotechnical Engineering, 1-13.

Gong, J., Nie, Z., Zhu, Y., Liang, Z., \& Wang, X. 2019. Exploring the effects of particle shape and content of sand on the shear behavior of sand-sand mixtures via the DEM. Computers and Geotechnics, 106: 161-176.

Goudarzy, M., König, D., \& Schanz, T. 2016. Small strain stiffness of granular materials containing sand. Soils and Foundations, 56(5): 756-764.

Hazirbaba, K., and Rathje, E. M. 2009. Pore pressure generation of silty sands due to induced cyclic shear strains. Journal of geotechnical and geoenvironmental engineering, 135(12): 1892-1905.

Kuerbis, R., Negussey, D., Vaid, Y. P. 1988. Effect of gradation and sand content on the undrained response of sand. In Hydraulic fill structures (pp. 330-345). Publ by ASCE.

Lashkari, A. 2014. Recommendations for extension and re-calibration of an existing sand constitutive model taking into account varying non-plastic sand content. Soil Dynamics and Earthquake Engineering, 61: 212-238.

Li, G., Liu, Y. J., Dano, C., Hicher, P. Y. 2015. Grading-dependent behavior of granular materials: from discrete to continuous modeling. Journal of Engineering Mechanics, 141(6): 04014172.

Mitchell, J. K., \& Soga, K. (1993). Fundamentals of Soil Behavior, John Wiley \& Sons. Inc., New York: 422.

Ng, T. T., Zhou, W., Chang, X. L. 2017. Effect of particle shape and sand content on the behavior of binary mixture. Journal of Engineering Mechanics, 143(1): C4016008.

Ni, Q., Tan, T. S., Dasari, G. R., Hight, D. W. (2004). Contribution of sand to the compressive 
strength of mixed soils. Géotechnique, 54(9): 561-569.

Rahman, M. M., Lo, S. C., Dafalias, Y. F. 2014. Modelling the static liquefaction of sand with lowplasticity sand. Géotechnique, 64(11):881-894.

Rahman, M. M., Lo, S. R., Gnanendran, C. T. 2008. On equivalent granular void ratio and steady state behaviour of loose sand with fines. Canadian Geotechnical Journal, 45(10): 1439-1456.

Roscoe, K., and Burland, J. B. 1968. On the generalized stress-strain behavior of wet clay.

Roscoe, K. H., Schofield, A., Thurairajah, A. 1963. Yielding of clays in states wetter than critical. Geotechnique, 13(3): 211-240.

Roscoe, K. H., Schofield, A., Wroth, A. P. 1958. On the yielding of soils. Geotechnique, 8(1): 2253.

Saberi, M., Annan, C. D., Konrad, J. M., Lashkari, A. 2016. A critical state two-surface plasticity model for gravelly soil-structure interfaces under monotonic and cyclic loading. Computers and Geotechnics, 80: 71-82.

Terzaghi, K. 1943. Theoretical Soil Mechanics. John Wiley \& Sons, Inc., New York,. doi:10.1002/9780470172766

Polito, C. P., and Sibley, E. L. 2020. Threshold sand content and behavior of sands with nonplastic silts. Canadian Geotechnical Journal, 57(3): 462-465.

Sitharam, T. G., Dash, H. K., Jakka, R. S. 2013. Postliquefaction undrained shear behavior of sandsilt mixtures at constant void ratio. International Journal of Geomechanics, 13(4): 421-429.

Thevanayagam, S. 1998. Effect of sand and confining stress on undrained shear strength of silty sands. Journal of Geotechnical and Geoenvironmental Engineering, 124(6): 479-491.

Thevanayagam, S. 2007. Intergrain contact density indices for granular mixes-I: Framework. 
Earthquake engineering and engineering vibration, 6(2): 123.

Thevanayagam, S., and Mohan, S. 2000. Intergranular state variables and stress-strain behaviour of silty sands. Geotechnique, 50(1): 1-23.

Thevanayagam, S., Shenthan, T., Mohan, S., Liang, J. 2002. Undrained fragility of clean sands, silty sands, and sandy silts. Journal of geotechnical and geoenvironmental engineering., 128(10): 849-859.

Vaid, Y. P. (1994, October). Liquefaction of silty soils. In Ground failures under seismic conditions (pp. 1-16). ASCE.

Vallejo, L. E. 2001. Interpretation of the limits in shear strength in binary granular mixtures. Canadian Geotechnical Journal, 38(5): 1097-1104.

Vasil'eva, A. A., Mikheev, V. V., Lobanova, G. L. 1971. How the strength properties of gravel soils depend on the type and state of the sand filling the pores. Soil Mechanics and Foundation Engineering, 8(3): 167-171.

Wei, L. M., and Yang, J. 2014. On the role of grain shape in static liquefaction of sand-fines mixtures. Géotechnique, 64(9), 740-745.

Xiao, Y., Sun, Y., Liu, H., Xiang, J., Ma, Q., Long, L. 2017. Model predictions for behaviors of sand-nonplastic-sand mixturesusing equivalent-skeleton void-ratio state index. Science China Technological Sciences, 60(6): 878-892.

Yang, J., and Wei, L. M. 2012. Collapse of loose sand with the addition of fines: the role of particle shape. Géotechnique, 62(12): 1111-1125.

Yang, J., Wei, L. M., Dai, B. B. 2015. State variables for silty sands: Global void ratio or skeleton void ratio? Soils and Foundations, 55(1): 99-111. 
Yang, J., Yin, Z. Y., Laouafa, F., Hicher, P. Y. 2020a. Three - dimensional hydromechanical modeling of internal erosion in dike - on - foundation. International Journal for Numerical and Analytical Methods in Geomechanics, 44(8): DOI: 10.1002/nag.3057.

Yang, J., Yin, Z. Y., Laouafa, F., Hicher, P. Y. 2020b. Hydromechanical modeling of granular soils considering internal erosion. Canadian Geotechnical Journal, 57(2): 157-172.

Yang, S. L., Sandven, R., Grande, L. 2006. Steady-state lines of sand-silt mixtures. Canadian Geotechnical Journal, 43(11): 1213-1219.

Yin, Z. Y., Zhao, J., Hicher, P. Y. 2014. A micromechanics-based model for sand-silt mixtures International journal of solids and structures, 51(6): 1350-1363.

Yin Z Y, Huang H W, Hicher P Y. 2016. Elastoplastic modeling of sand-silt mixtures. Soils and Foundations, 56(3): 520-532.

Zlatović, S., and Ishihara, K. 1995. On the influence of nonplastic sand on critical state strength. In First International Conference on Earthquake Geotechnical Engineering, 95:239-244. 


\section{List of Figures}

Fig. 1. Schematic diagram of skeleton structure classification of a mixed soil (after

Thevanayagam, 2007)

Fig. 2. Schematic diagram of "wall effect" and "loosening effect" during the packing of mixed soils

Fig. 3. Variation of minimum void ratio with $s c$ under different GSD parameters

Fig. 4. Variation of $\alpha$ and $\beta$ with typical GSD parameters

Fig. 5. Comparison between experimental and predicted $\alpha$ and $\beta$ parameters using Equations (10) and (11)

Fig. 6. Comparison between experimental minimum void ratios of specimens in Table 1 and predicted minimum void ratios with the help of Equations (10) and (11)

Fig. 7. Grain size distribution of gravelly sands with different $s c$ used to further verify Equations (10) and (11)

Fig. 8. Predicted and experimental minimum void ratios of an additional series of vibrating compaction test

Fig. 9. Grain size distributions of gravelly sands with varying sc in drained triaxial tests

Fig. 10. Stress-strain responses $\left(q-\varepsilon_{1}\right.$ and $\left.\varepsilon_{v}-\varepsilon_{1}\right)$ for specimens prepared with different $s c$ and the same $e$ in Test Series A

Fig. 11. Stress-strain responses ( $\mathrm{q}-\varepsilon_{1}$ and $\left.\varepsilon_{v}-\varepsilon_{1}\right)$ of specimens prepared with the same $e_{s k}$ calculated from Equations (12) and (13) under confining pressure of $150 \mathrm{kPa}$

Fig. 12. Stress-strain responses $\left(q-\varepsilon_{1}\right.$ and $\left.\varepsilon_{v}-\varepsilon_{1}\right)$ of specimens prepared with the same $e_{s k}$ calculated from Equations (2) and (4) which do not consider the effect of GSD under confining pressure of $150 \mathrm{kPa}$

Fig. 13. CSLs of gravelly sand drawn in terms of the void ratio versus mean principal effective 
stress $p^{\prime}$

Fig. 14 CSLs of gravelly sand drawn in terms of the $e_{s k}$ versus mean principal effective stress $p$ '
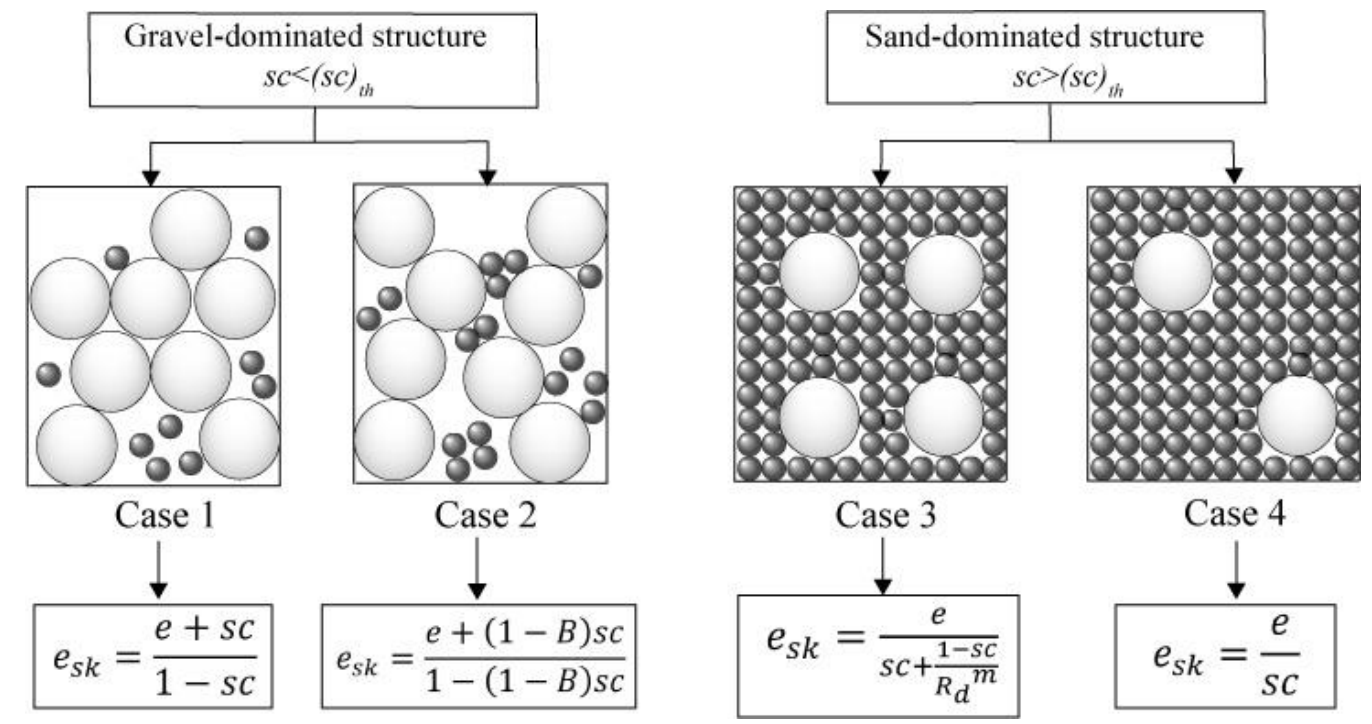

Fig. 1 Schematic diagram of skeleton structure classification of a mixed soil (after Thevanayagam, 2007) 

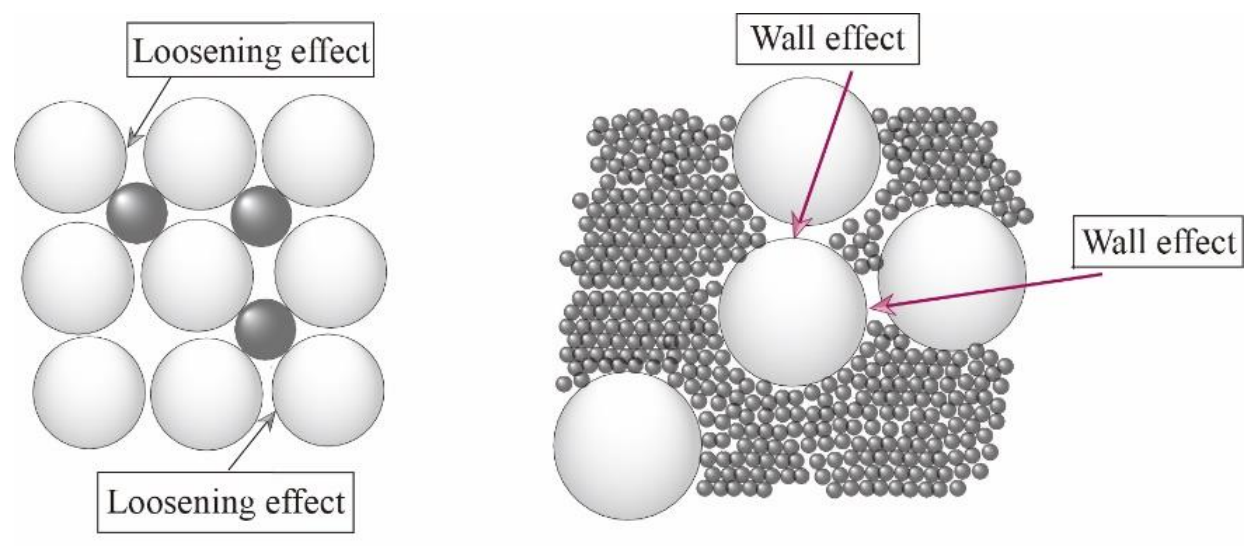

Fig. 2 Schematic diagram of "wall effect" and "loosening effect" during the packing of mixed soils 


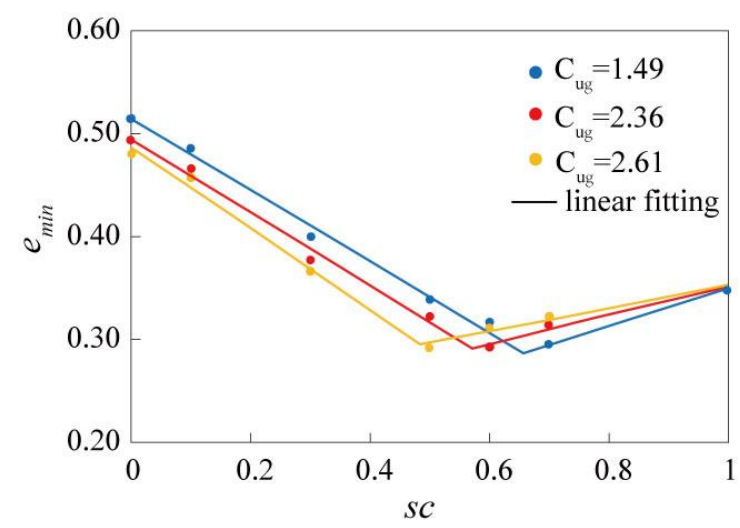

(a) Effect of $C_{u g}\left(C_{u s}=7.01\right.$ and $\left.R_{d}=5.46\right)$

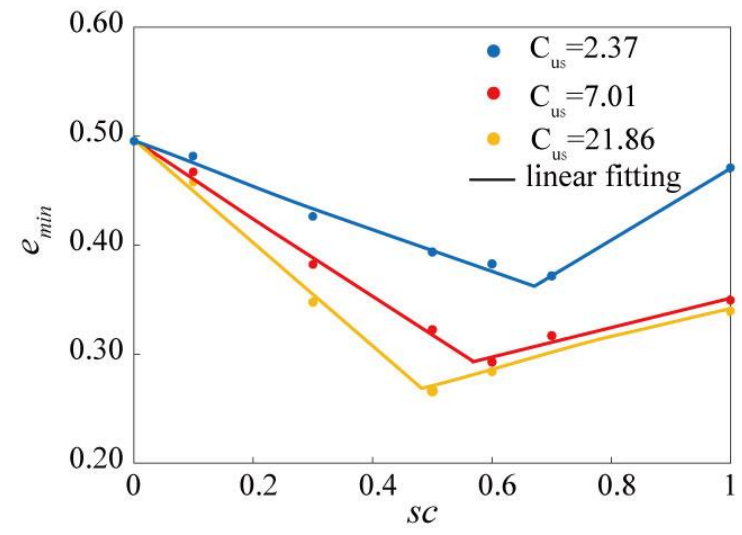

(b) Effect of $C_{u s}\left(C_{u g}=2.36\right.$ and $\left.R_{d}=5.46\right)$

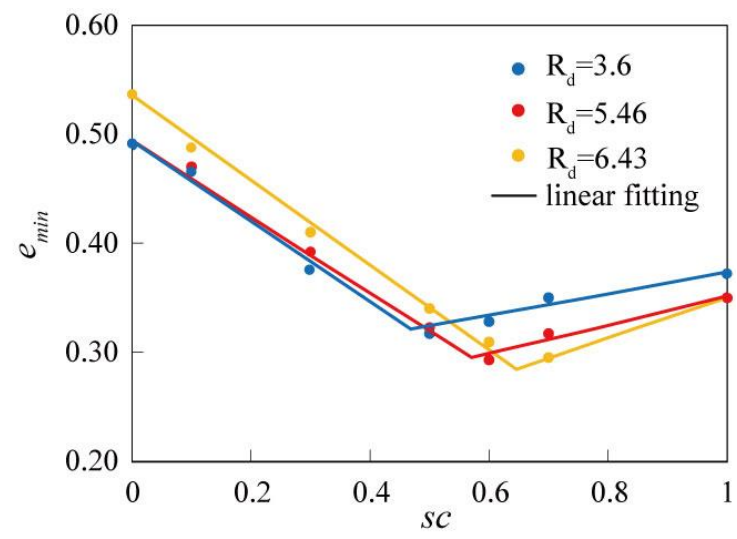

(c) Effect of $R_{d}\left(C_{u g}=2.36\right.$ and $\left.C_{u s}=7.01\right)$

Fig. 3 Variation of minimum void ratio with $s c$ under different GSD parameters: (a) Effect of $C_{u g}\left(C_{u s}=7.01\right.$ and $\left.R_{d}=5.46\right)$; (b) Effect of $C_{u s}\left(C_{u g}=2.36\right.$ and $\left.R_{d}=5.46\right)$; (c) Effect of $R_{d}\left(C_{u g}=2.36\right.$ and $\left.C_{u s}=7.01\right)$ 


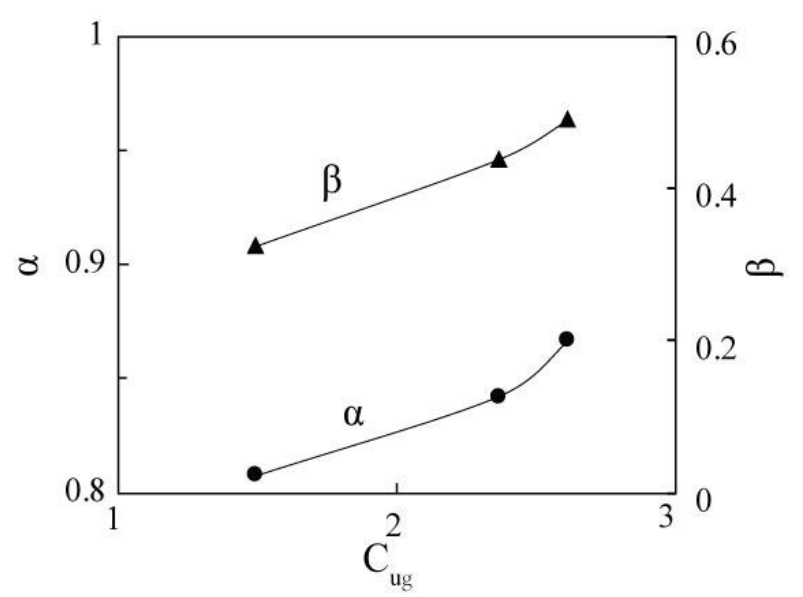

(a) $\alpha, \beta$ versus $C_{u g}$

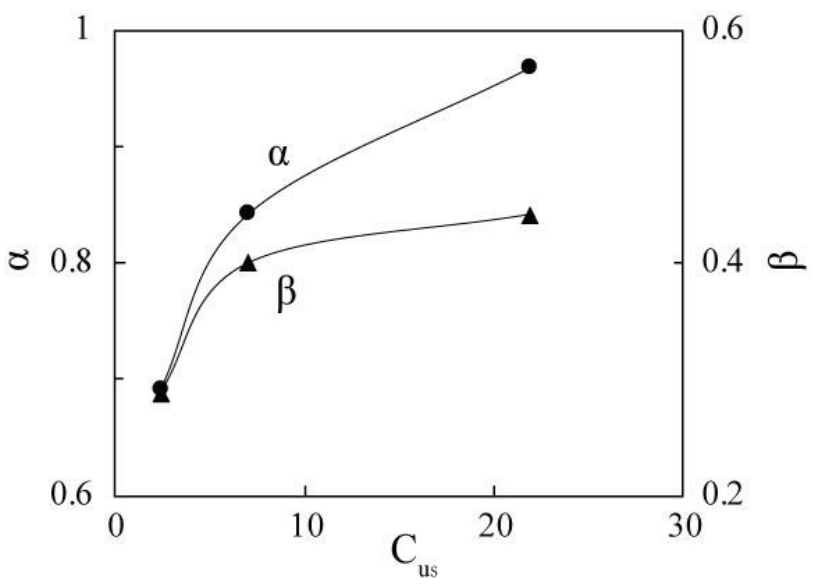

(b) $\alpha, \beta$ versus $C_{u s}$

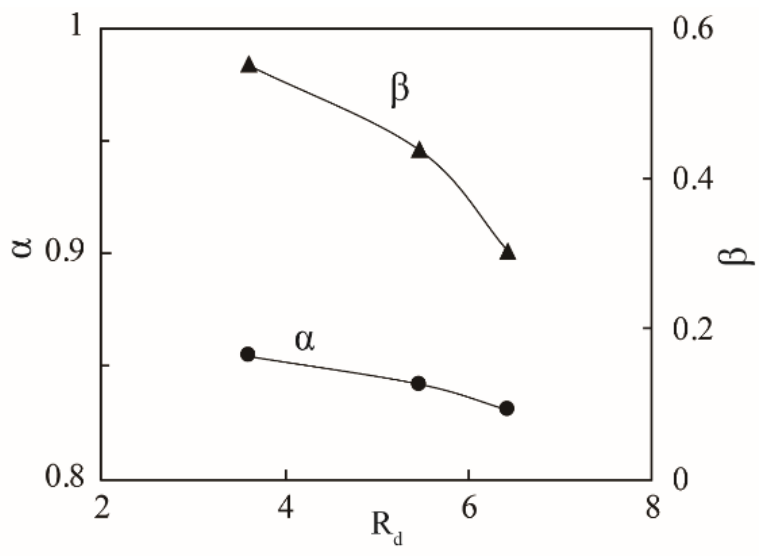

(c) $\alpha, \beta$ versus $R_{d}$

Fig. 4 Variation of $\boldsymbol{\alpha}$ and $\boldsymbol{\beta}$ with typical GSD parameters: (a) $\alpha, \beta$ versus $C_{u g}$; (b) $\alpha, \beta$ versus $C_{u s} ;$ (c) $\alpha, \beta$ versus $R_{d}$ 


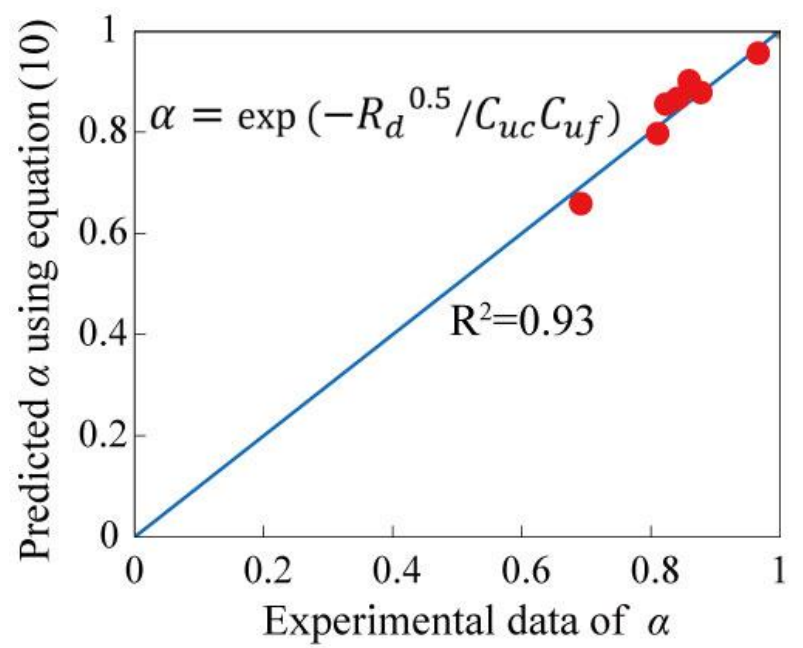

(a) $\alpha$

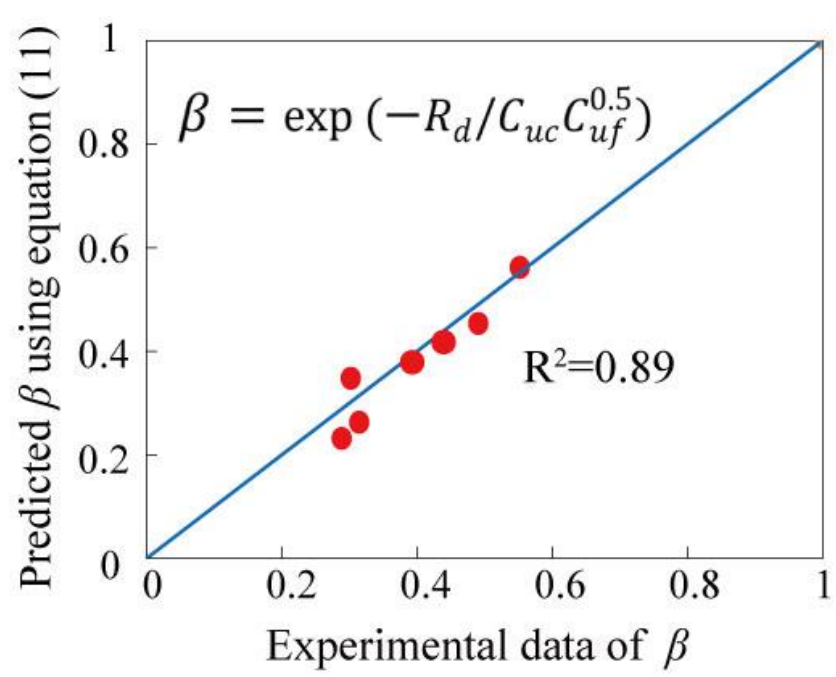

(b) $\beta$

Fig. 5 Comparison between experimental and predicted $\alpha$ and $\beta$ parameters using Equations (10) and (11): (a) $\alpha$; (b) $\beta$ 


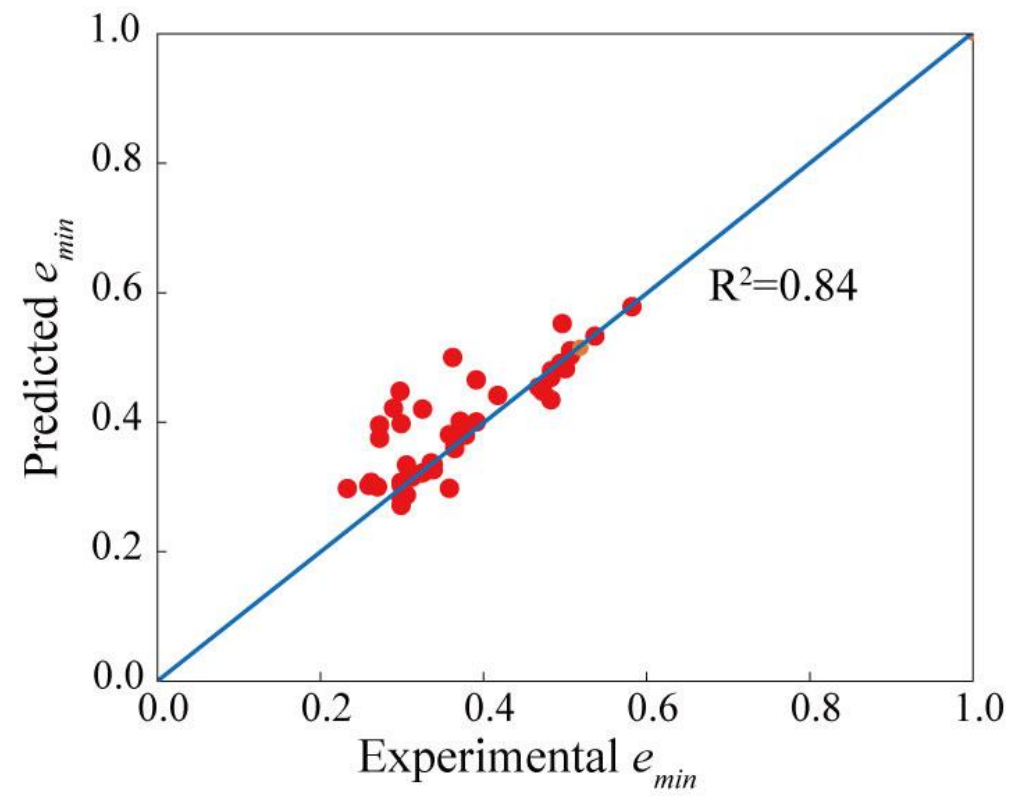

Fig. 6 Comparison between experimental minimum void ratios of specimens in Table 1 and predicted minimum void ratios with the help of Equations (10) and (11). 


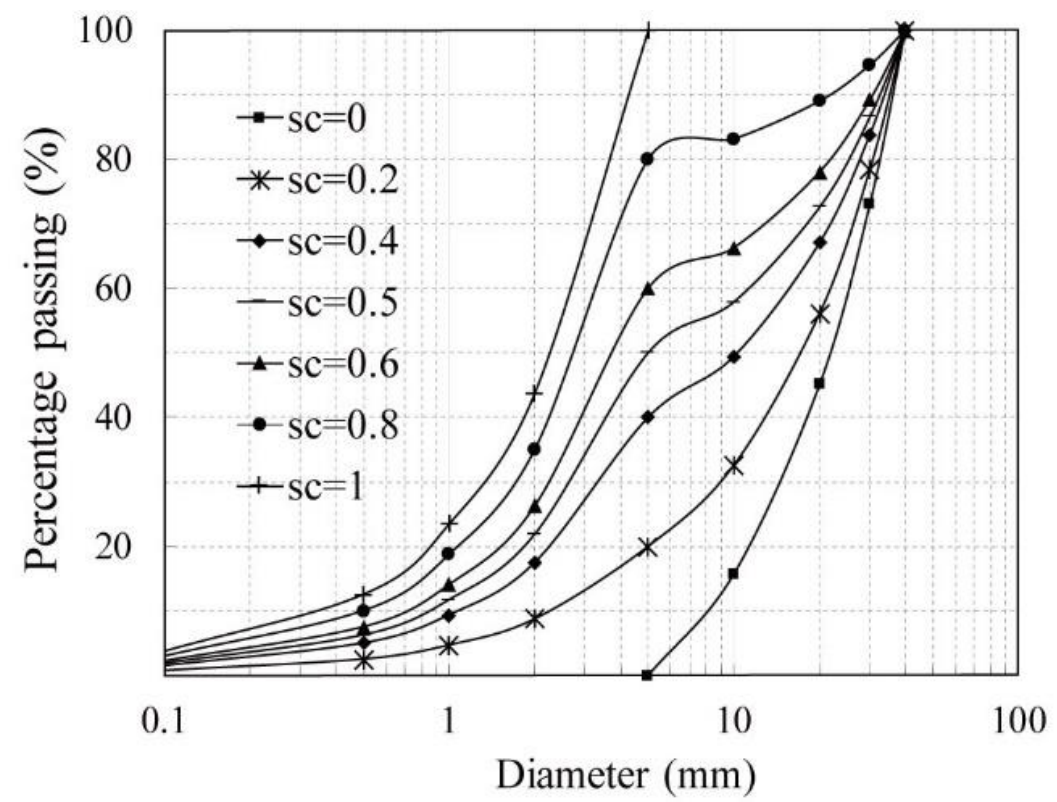

Fig. 7 Grain size distribution of gravelly sands with different $s c$ used to further verify Equations (10) and (11). 


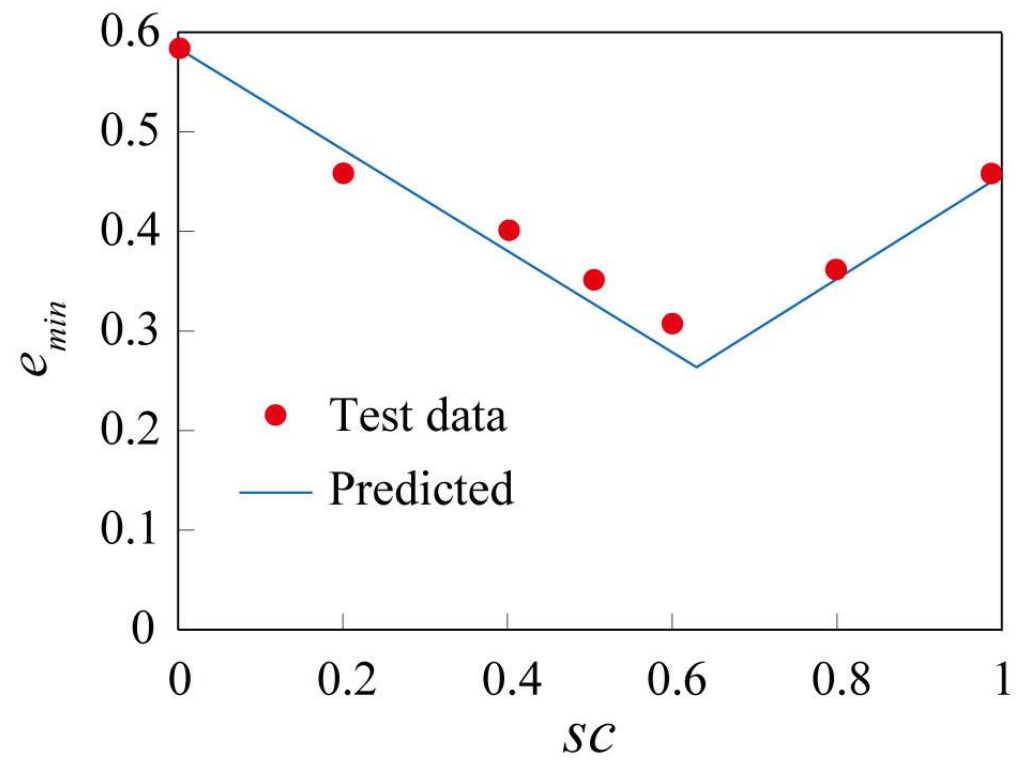

Fig. 8 Predicted and experimental minimum void ratios of an additional series of vibrating compaction test. 


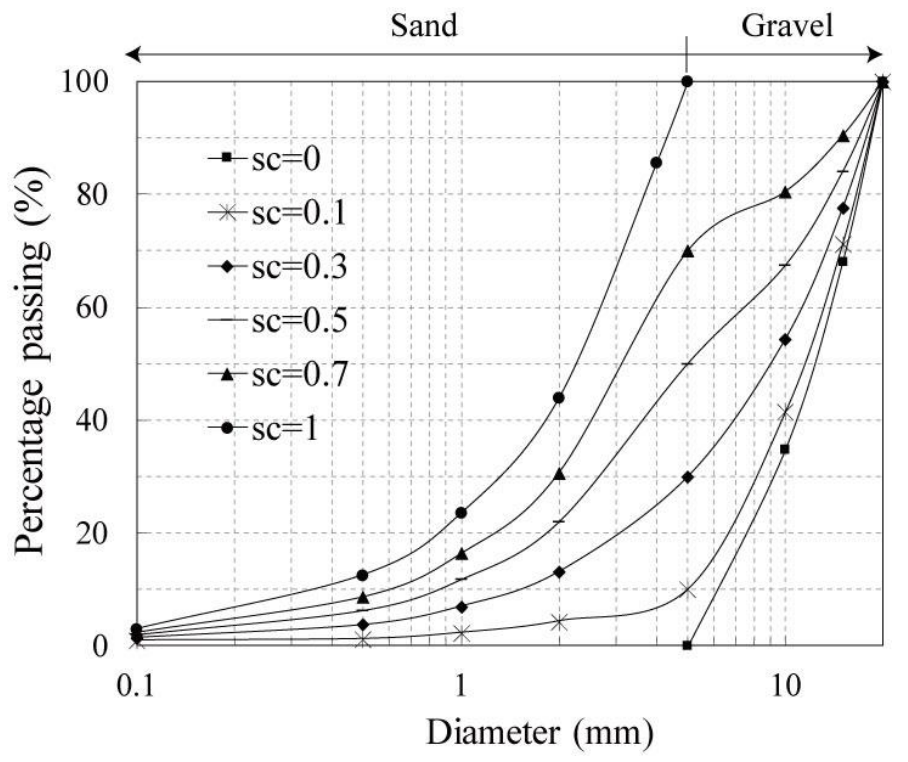

Fig. 9 Grain size distributions of gravelly sands with varying sc in drained triaxial tests (index properties of gravel and sand are recalled in Table 3). 


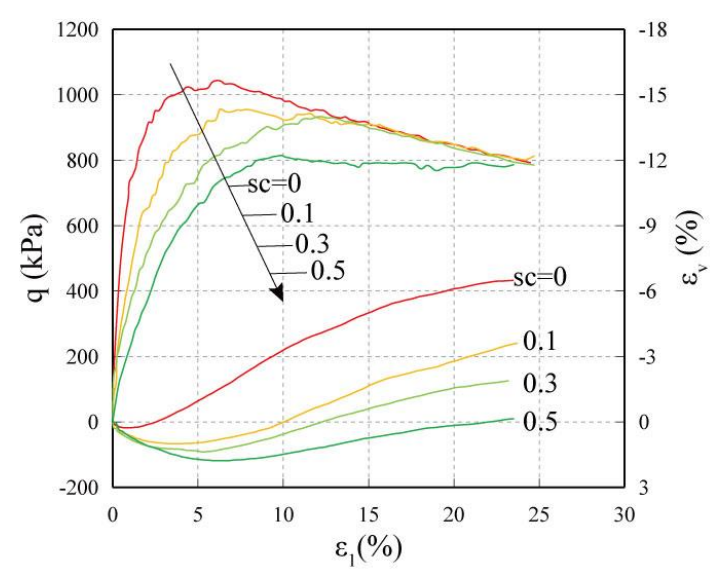

(a) $\sigma_{3}=150 \mathrm{kPa}$, gravel-dominated

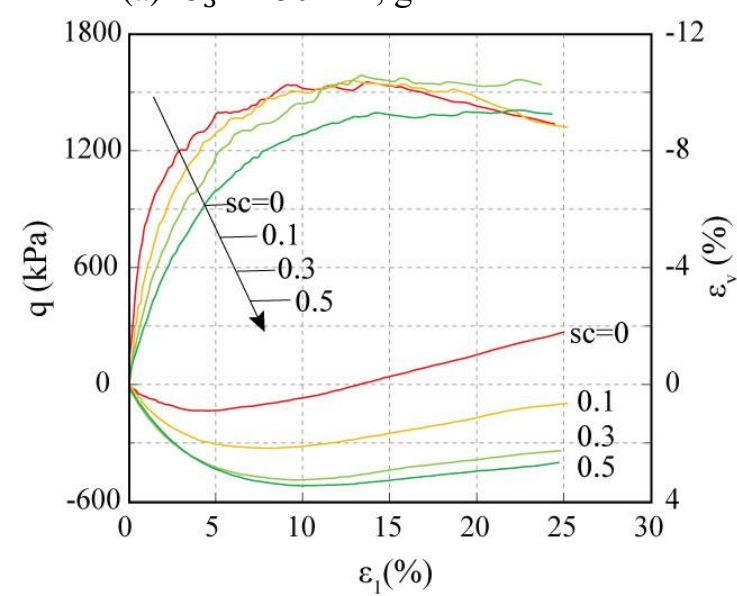

(c) $\sigma_{3}=300 \mathrm{kPa}$, gravel-dominated

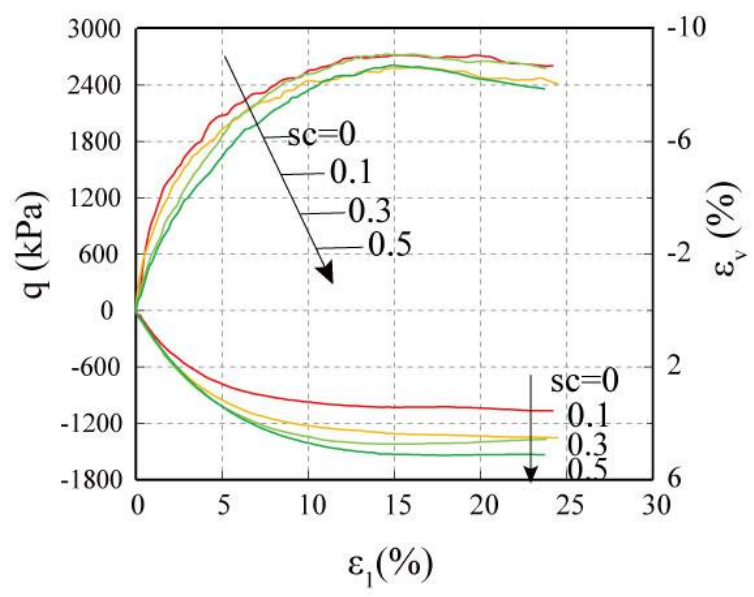

(e) $\sigma_{3}=600 \mathrm{kPa}$, gravel-dominated

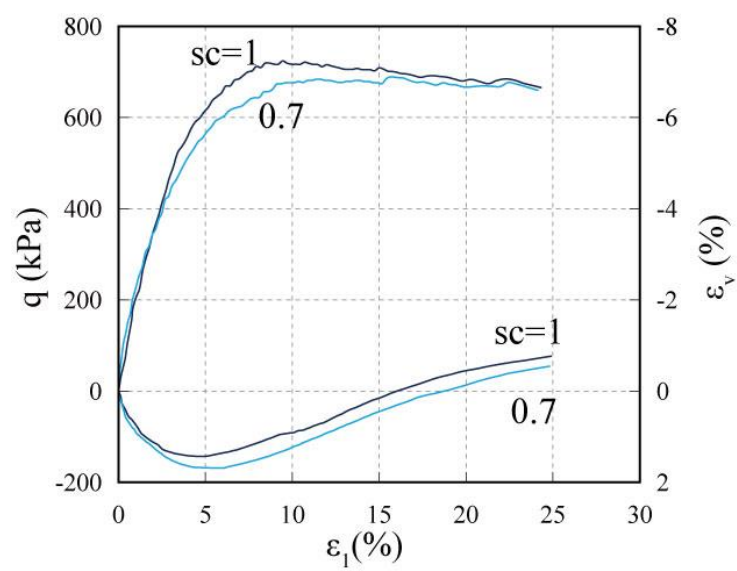

(b) $\sigma_{3}=150 \mathrm{kPa}$, sand-dominated

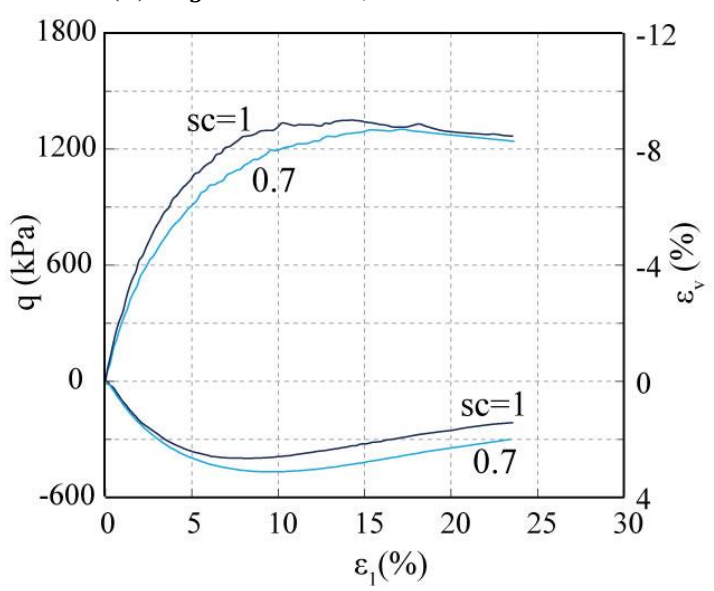

(d) $\sigma_{3}=300 \mathrm{kPa}$, sand-dominated

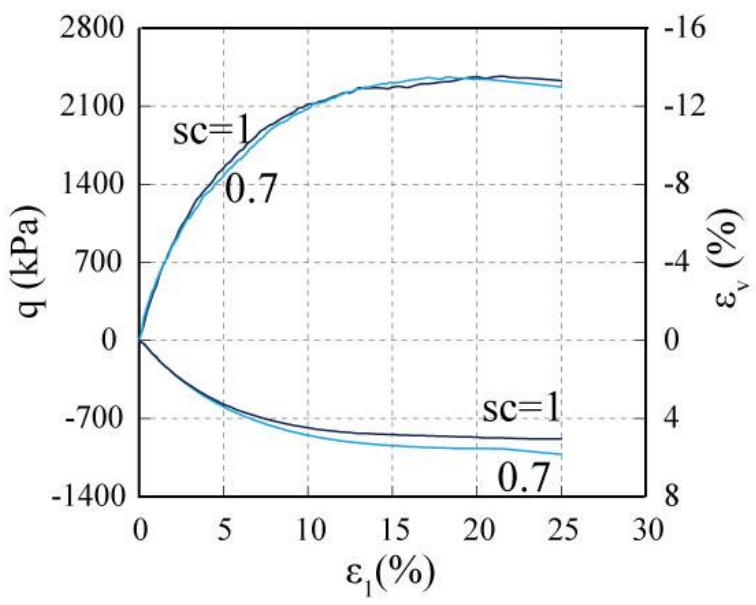

(f) $\sigma_{3}=600 \mathrm{kPa}$, sand-dominated

Fig. 10 Stress-strain responses $\left(q-\varepsilon_{1}\right.$ and $\left.\varepsilon_{v}-\varepsilon_{1}\right)$ for specimens prepared with different $s c$ and the same $\boldsymbol{e}$ in Test Series A: (a) $\sigma_{3}=150 \mathrm{kPa}$, gravel-dominated; (b) $\sigma_{3}=150 \mathrm{kPa}$, sand-dominated; (c) $\sigma_{3}=300 \mathrm{kPa}$, gravel-dominated; (d) $\sigma_{3}=300 \mathrm{kPa}$, sand-dominated; (e) $\sigma_{3}=600 \mathrm{kPa}$, gravel-dominated; (f) $\sigma_{3}=600 \mathrm{kPa}$, sand-dominated 


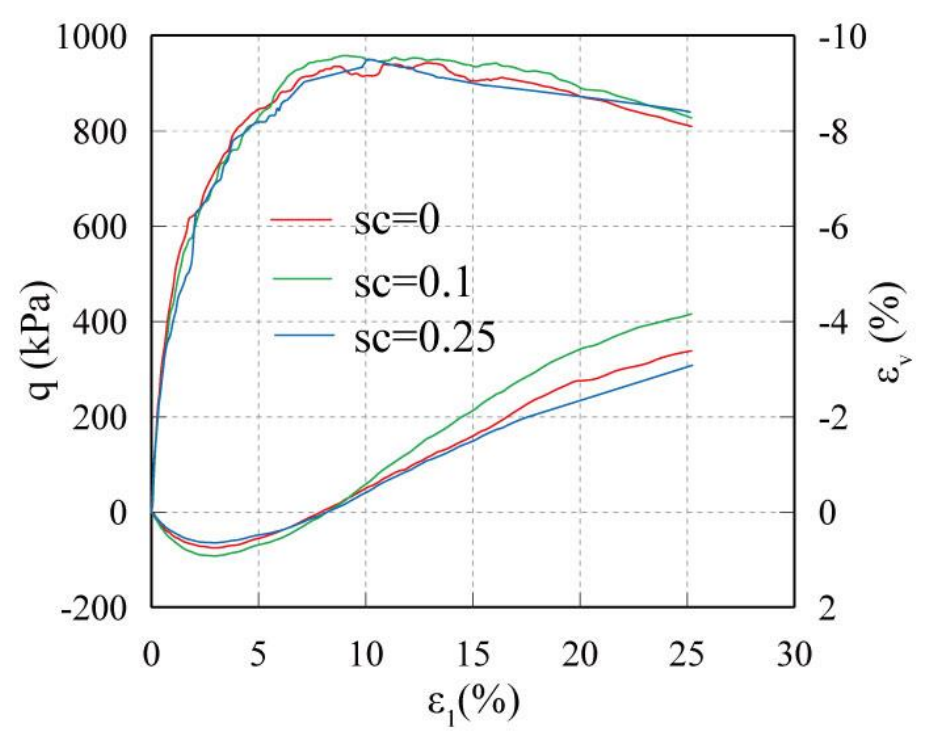

(a) gravel-dominated structure

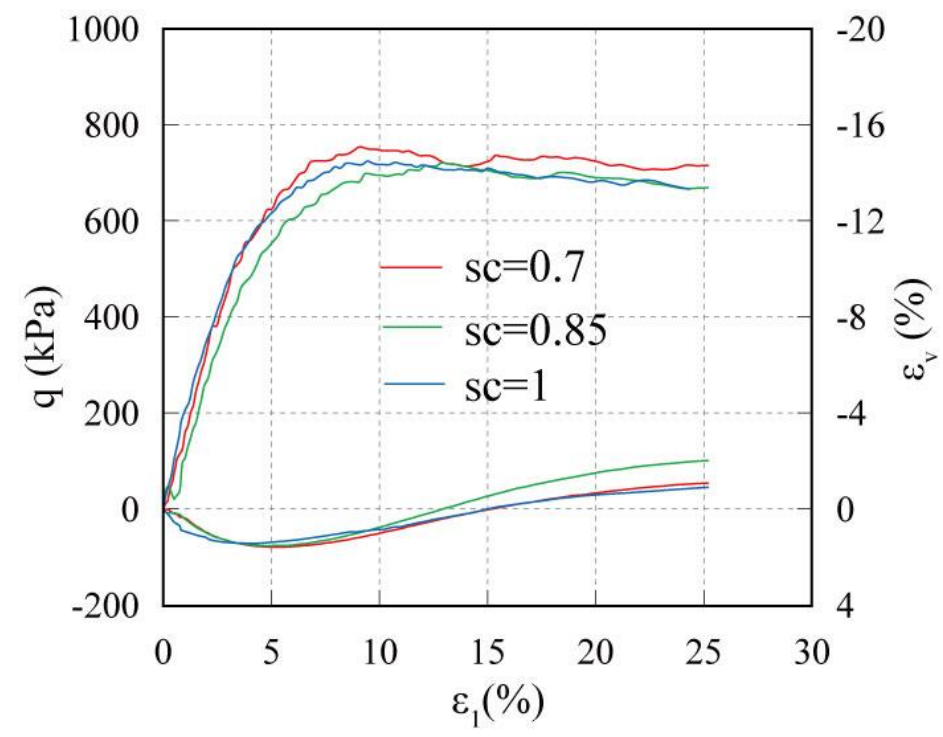

(b) sand-dominated structure

Fig. 11 Stress-strain responses $\left(q-\varepsilon_{1}\right.$ and $\left.\varepsilon_{v}-\varepsilon_{1}\right)$ of specimens prepared with the same $e_{s k}$ calculated from Equations (12) and (13) under confining pressure of $150 \mathrm{kPa}$. (a) graveldominated structure; (b) sand-dominated structure. 


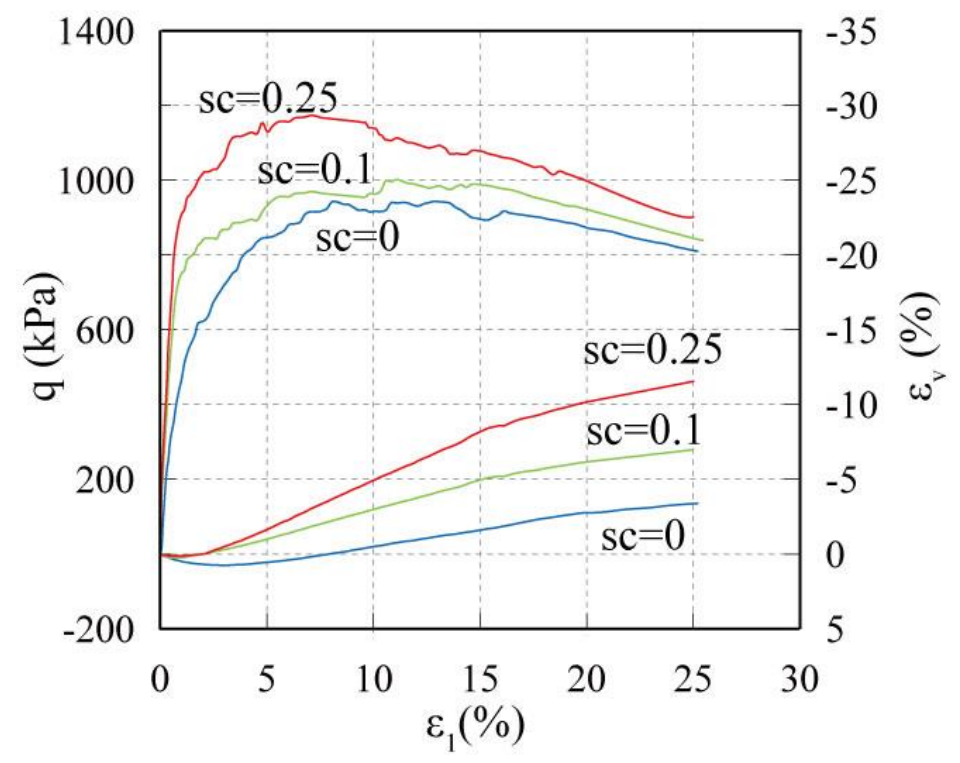

(a) gravel-dominated structure

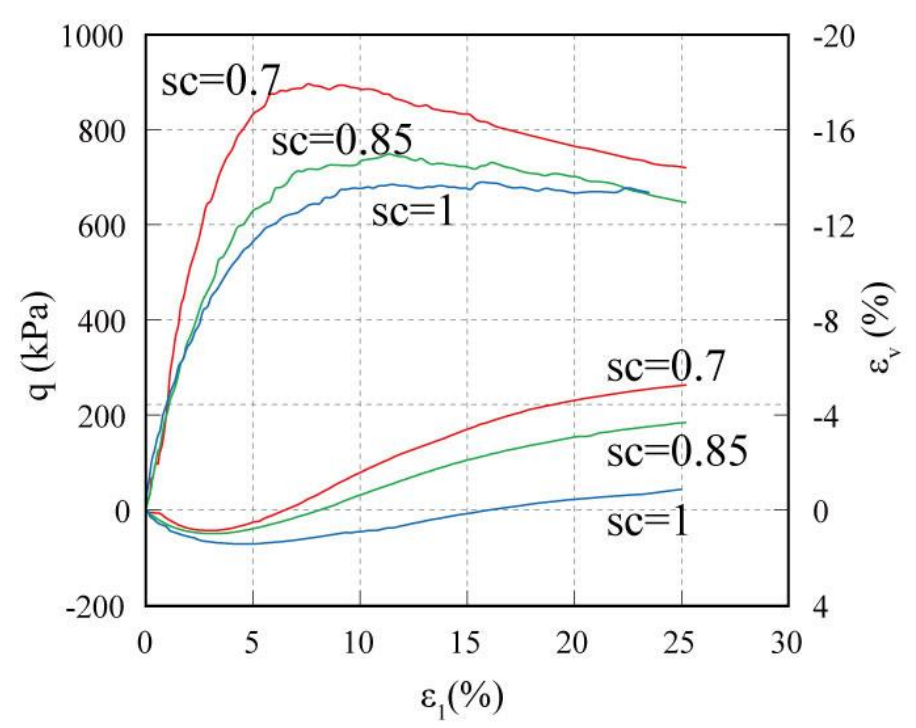

(b) sand-dominated structure

Fig. 12 Stress-strain responses $\left(q-\varepsilon_{1}\right.$ and $\left.\varepsilon_{v}-\varepsilon_{1}\right)$ of specimens prepared with the same $e_{s k}$ calculated from Equations (2) and (4) which do not consider the effect of GSD under confining pressure of $150 \mathrm{kPa}$. (a) gravel-dominated structure; (b) sand-dominated structure. 


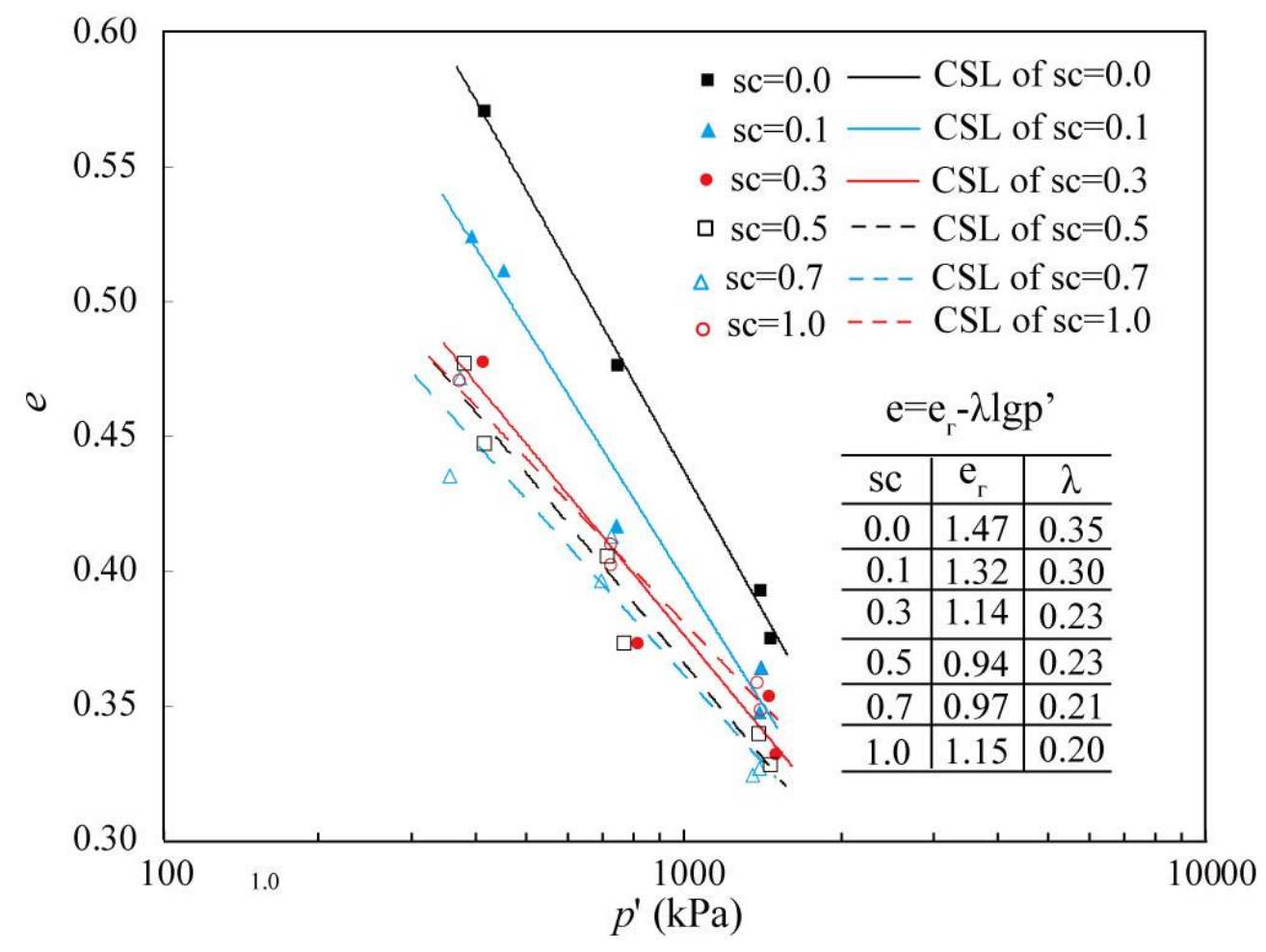

Fig. 13 CSLs of gravelly sand drawn in terms of the void ratio versus mean effective stress $p$ '. 


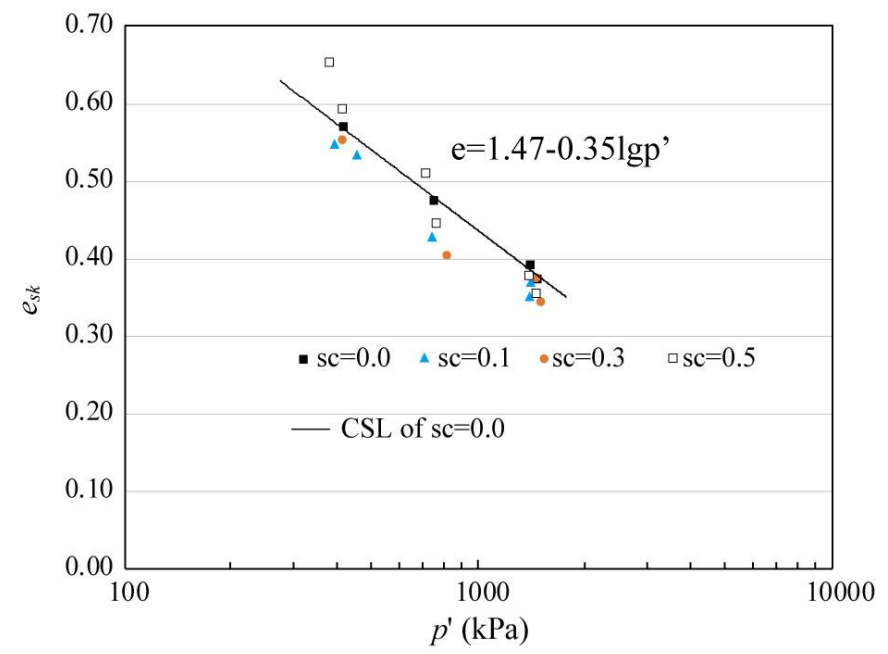

(a) gravel-dominated, $e_{s k}$ calculated from Equation (12), consider the effect of GSD

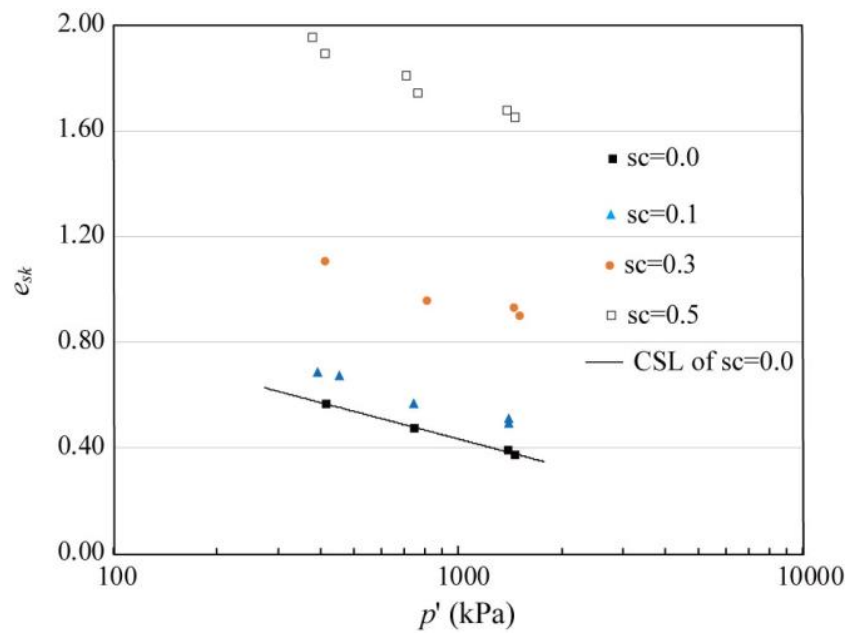

(c) gravel-dominated, $e_{s k}$ calculated from Equation (2), not consider the effect of GSD

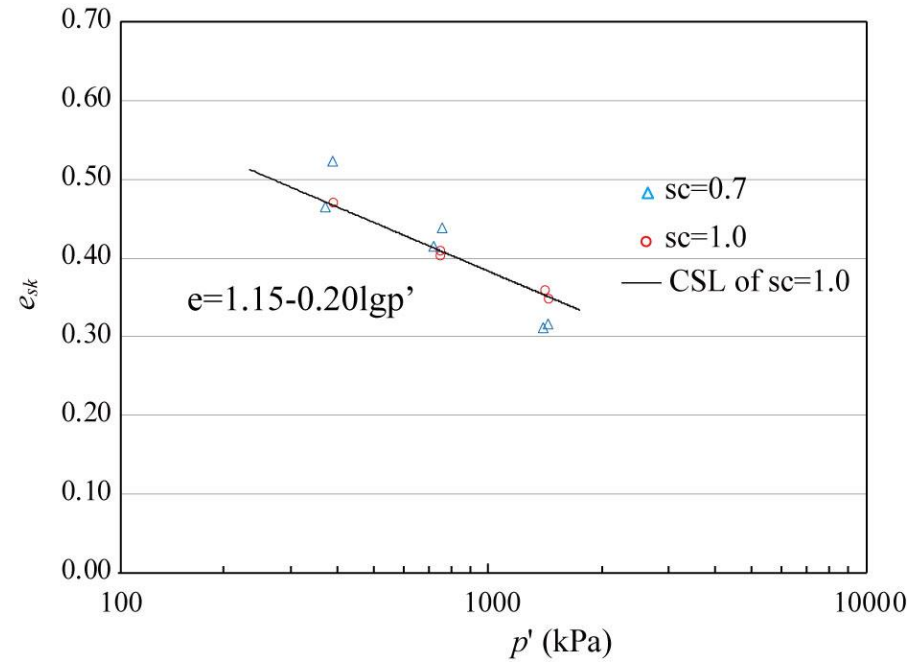

(b) sand-dominated, $e_{s k}$ calculated from Equation (13), consider the effect of GSD

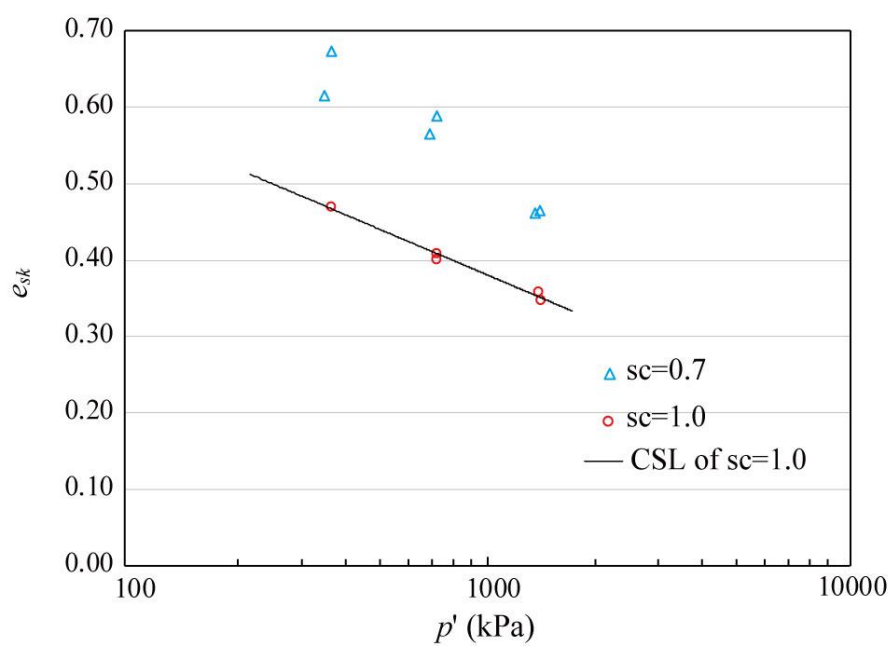

(d) sand-dominated, $e_{s k}$ calculated by Equation (4), not consider the effect of GSD

Fig. 14 CSLs of gravelly sand drawn in terms of the $e_{s k}$ versus mean effective stress $p^{\prime}$. (a) gravel-dominated, $e_{s k}$ calculated from Equation (12), consider the effect of GSD; (b) sanddominated, $e_{s k}$ calculated from Equation (13), consider the effect of GSD; (c) gravel-dominated, $e_{s k}$ calculated from Equation (2), not consider the effect of GSD; (d) sand-dominated, $e_{s k}$ calculated by Equation (4), not consider the effect of GSD 


\section{List of Tables}

Table 1. Vibrating compaction test program

\begin{tabular}{cccc}
\hline Test number & $C_{u g}$ & $C_{u s}$ & $R_{d}$ \\
\hline $\mathrm{T}_{1}$ & 1.49 & 7.01 & 5.46 \\
$\mathrm{~T}_{2}$ & 2.36 & 7.01 & 5.46 \\
$\mathrm{~T}_{3}$ & 2.61 & 7.01 & 5.46 \\
$\mathrm{~T}_{4}$ & 2.36 & 2.37 & 5.46 \\
$\mathrm{~T}_{5}$ & 2.36 & 21.86 & 5.46 \\
$\mathrm{~T}_{6}$ & 2.36 & 7.01 & 3.60 \\
$\mathrm{~T}_{7}$ & 2.36 & 7.01 & 6.43 \\
\hline
\end{tabular}

Table 2 Experimental program

\begin{tabular}{lcc}
\hline \multicolumn{1}{c}{ Objective } & Test Series & $\begin{array}{c}\text { Sand } \\
\text { content }\end{array}$ \\
\hline & & 0.0 \\
Study stress-strain responses of gravelly & & 0.1 \\
sands prepared at the same global void ratio & Test Series A $(e=0.490)$ & 0.3 \\
with different sand contents & & 0.5 \\
& & 0.7 \\
& & 1.0 \\
\hline Study stress-strain responses of gravelly & Test Series B $\left(e_{s k}=0.547\right)$ & 0.0 \\
sands prepared with the same skeleton void & Coarse grain supported fabric & 0.1 \\
ratio in a coarse grain supported fabric & & 0.25 \\
\hline Study stress-strain responses of gravelly & \multirow{2}{*}{ Test Series C $\left(e_{s k}=0.496\right)$} & 0.7 \\
sands prepared with the same skeleton void & Fine grain supported fabric & 0.85 \\
ratio in a fine grain supported fabric & & 1.0 \\
\hline
\end{tabular}


Table 3 Index properties of gravel and sand

\begin{tabular}{|c|c|c|}
\hline Property & Gravel & Sand \\
\hline$e_{\max }$ & 0.68 & 0.60 \\
\hline$e_{\min }$ & 0.49 & 0.35 \\
\hline$d_{60}(\mathrm{~mm})$ & 14.40 & 2.65 \\
\hline$d_{30}(\mathrm{~mm})$ & 9.12 & 1.30 \\
\hline$d_{10}(\mathrm{~mm})$ & 6.10 & 0.38 \\
\hline$C_{u}$ & 2.37 & 7.01 \\
\hline$C_{c}$ & 0.95 & 1.68 \\
\hline$R_{d}$ & \multicolumn{2}{|c|}{5.46} \\
\hline
\end{tabular}

Table 4 Global void ratios and skeleton void ratios of specimens in Test Series A-C before and after consolidation

\begin{tabular}{|c|c|c|c|c|c|}
\hline Test Series & $\begin{array}{l}\text { After sample } \\
\text { preparation }\end{array}$ & $\begin{array}{l}\text { Sand } \\
\text { content }\end{array}$ & $\begin{array}{l}\text { After consolidation } \\
\qquad(150 \mathrm{kPa})\end{array}$ & $\begin{array}{l}\text { After consolidation } \\
\qquad(300 \mathrm{kPa})\end{array}$ & $\begin{array}{l}\text { After consolidation } \\
\qquad(600 \mathrm{kPa})\end{array}$ \\
\hline \multirow{6}{*}{ Test Series A } & \multirow{6}{*}{$e=0.490$} & 0.0 & $e=0.475$ & $e=0.461$ & $e=0.450$ \\
\hline & & 0.1 & $e=0.473$ & $e=0.457$ & $e=0.444$ \\
\hline & & 0.3 & $e=0.462$ & $e=0.453$ & $e=0.441$ \\
\hline & & 0.5 & $e=0.460$ & $e=0.452$ & $e=0.441$ \\
\hline & & 0.7 & $e=0.465$ & $e=0.456$ & $e=0.445$ \\
\hline & & 1.0 & $e=0.464$ & $e=0.457$ & $e=0.446$ \\
\hline \multirow{3}{*}{ Test Series B } & \multirow{3}{*}{$e_{s k}=0.547$} & 0.0 & $e_{s k}=0.541$ & \multirow{3}{*}{ / } & \multirow{3}{*}{ / } \\
\hline & & 0.1 & $e_{s k}=0.543$ & & \\
\hline & & 0.25 & $e_{s k}=0.546$ & & \\
\hline \multirow{3}{*}{ Test Series C } & \multirow{3}{*}{$e_{s k}=0.496$} & 0.7 & $e_{s k}=0.486$ & \multirow{3}{*}{ l } & \multirow{3}{*}{ l } \\
\hline & & 0.85 & $e_{s k}=0.484$ & & \\
\hline & & 1.0 & $e_{s k}=0.490$ & & \\
\hline
\end{tabular}

Table 5. Skeleton void ratios of specimens with different sc in Test series A

\begin{tabular}{|c|c|c|c|}
\hline Global void ratio $e$ & $s c$ & Type of dominated structure & Skeleton void ratio $e_{s k}$ \\
\hline \multirow{6}{*}{0.49} & 0.0 & \multirow{4}{*}{ Gravel-dominated } & 0.49 \\
\hline & 0.1 & & 0.52 \\
\hline & 0.3 & & 0.59 \\
\hline & 0.5 & & 0.73 \\
\hline & 0.7 & \multirow{2}{*}{ Sand-dominated } & 0.55 \\
\hline & 1.0 & & 0.49 \\
\hline
\end{tabular}




\section{Appendix}

Repeated drained triaxial test results are shown in Fig. A1 on the same specimen with the same method and device under different confining pressures $\sigma_{3}$. It shows that the differences in deviatoric stress $q\left(q=\sigma_{1}-\sigma_{3}\right)$ and volumetric strain $\varepsilon_{v}$ between repeated specimens are minor and negligible, indicating a good reproducibility of conducted tests.

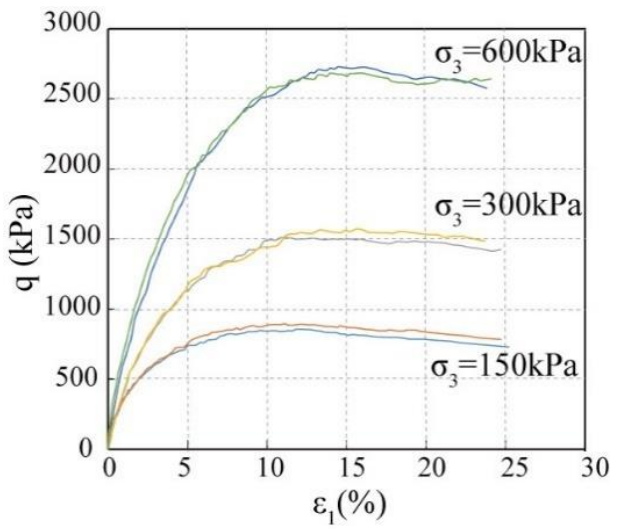

(a)

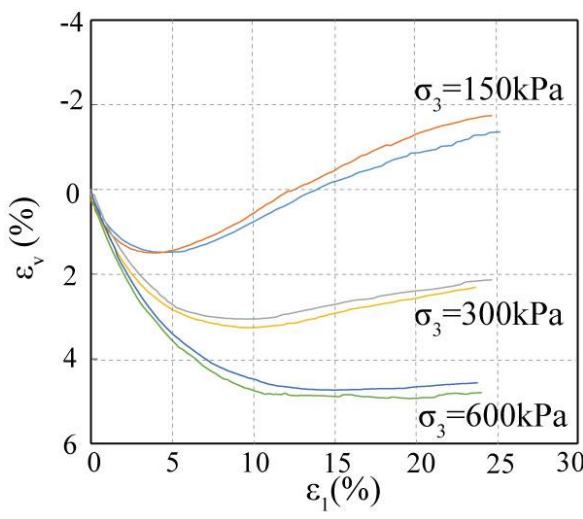

(b)

Fig. A1 Reproducibility assessment on deviatoric stress $q$ and volumetric strain $\varepsilon_{v}$ with axial strain $\varepsilon_{1}$ of repeated specimens with the same test method and device under different confining pressures: (a) deviatoric stress versus axial strain; (b) volumetric strain versus axial strain. 